\title{
Fully Coupled Finite Element Model to Study Multiple Hydraulic Fracturing in Heterogeneous Tight Formations
}

\author{
Ruizhi Zhong \\ West Virginia University
}

Follow this and additional works at: https://researchrepository.wvu.edu/etd

\section{Recommended Citation}

Zhong, Ruizhi, "Fully Coupled Finite Element Model to Study Multiple Hydraulic Fracturing in Heterogeneous Tight Formations" (2014). Graduate Theses, Dissertations, and Problem Reports. 122. https://researchrepository.wvu.edu/etd/122

This Thesis is protected by copyright and/or related rights. It has been brought to you by the The Research Repository @ WVU with permission from the rights-holder(s). You are free to use this Thesis in any way that is permitted by the copyright and related rights legislation that applies to your use. For other uses you must obtain permission from the rights-holder(s) directly, unless additional rights are indicated by a Creative Commons license in the record and/ or on the work itself. This Thesis has been accepted for inclusion in WVU Graduate Theses, Dissertations, and Problem Reports collection by an authorized administrator of The Research Repository @ WVU. For more information, please contact researchrepository@mail.wvu.edu. 
Fully Coupled Finite Element Model to Study Multiple Hydraulic Fracturing in Heterogeneous Tight Formations

\title{
Ruizhi Zhong
}

Thesis submitted to the

Benjamin M. Statler College of Engineering and Mineral Resources at

West Virginia University

in partial fulfillment of the requirements for the degree of

\author{
Master of Science \\ In \\ Petroleum and Natural Gas Engineering
}

Ebrahim Fathi, PhD., Chair

Kashy Aminian, PhD.

Ali Takbiri Borujeni, PhD.

Department of Petroleum and Natural Gas Engineering

Morgantown, West Virginia

2014

Keywords: Hydraulic fracturing; finite element method; fault reactivation

Copyright 2014 Ruizhi Zhong 


\section{ABSTRACT \\ Fully Coupled Finite Element Model to Study Multiple Hydraulic Fracturing in Heterogeneous Tight Formations}

\section{Ruizhi Zhong}

Hydraulic fracturing is a widely used technique in industry to enhance oil and gas recovery. The process involves the injection of fracking fluid with high pressure into the wellbore to propagate initial fractures generated during well perforation. It is a coupled process of fluid and rock mechanics one controlling the fluid movement and other fracture propagation. There is a lack of reliable and robust simulation technique that can couple these two processes at the same time being practical for large domain size of hydraulic fracturing in the field scale. In hydraulic fracturing, multiple fractures are also created within one cluster in a stage which increases the dimension of the problem. In addition to simulation difficulties of the process, there are concerns from operational point of view to choose the best technique to be able to place as many effective fractures as possible considering mechanical interactions between fractures that can impact the fracture geometries and ultimately production performance. The objectives of this thesis work therefore are to model multi-fracture hydraulic fracturing process in heterogeneous tight formations and optimize the process by sensitivity analysis on parameters such as fracture number and fracture spacing during hydraulic fracturing operations.

In this study, a fully coupled finite element model was built to simulate multiple hydraulic fracturing and possible fault reactivation zones are determined based on the slip-tendency analysis. Cases with different fracture number, fracture spacing and heterogeneity (materials number, Poisson's ratio, Young's modulus) are simulated. The results show that the number of hydraulic fractures and their spacing significantly impacts fractures geometry. The fracture number has positive relationship with propagation rate and negative relationship with fracture width while fracture spacing has negative relationship with propagation rate and positive relationship with fracture width.

The composite reservoir simulations indicate that heterogeneous condition in reservoir has minimum effect on fracture propagation if the fracture does not cross the boundary. However, if fracture passes through the interface between two materials distinguished by different Young Modulus both magnitude and rate of fracture propagation would change significantly. Sliptendency analysis performed clearly show the possible fault reactivation zones are around edge fractures tips. This study provides us understanding of multiple hydraulic fracturing investigating fracture geometry and stress change, and it is important for the development of sound numerical hydraulic fracturing optimization models. 


\section{ACKNOWLEDGEMENTS}

I would like to express my gratitude to my research advisor Dr. Ebrahim Fathi for being the chair for my master degree defense, and for his patient and earnest guidance on my research. I am sincerely grateful to my committee members Dr. Kashy Aminian and Dr. Ali Takbiri Borujeni for their support and guidance on my research. Special thanks to members in Dr. Fathi's group for their help in my research. I also want to take this opportunity to thank my family for their constant support in all my successes in life.

I would like to thank RPSEA's Funding for this project. RPSEA (www.rpsea.org) is a multipurpose entity whose mission is to provide stewardship in ensuring the focused research, development and deployment of safe and environmentally responsible technology that can effectively deliver hydrocarbons from domestic resources to the citizens of the United States. 


\section{TABLE OF CONTENTS}

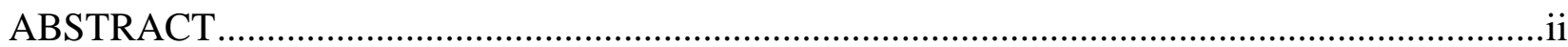

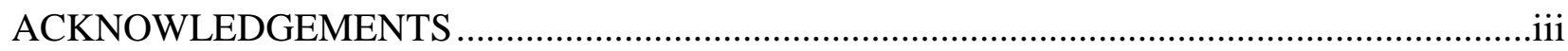

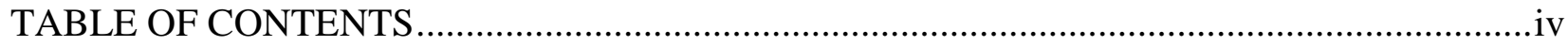

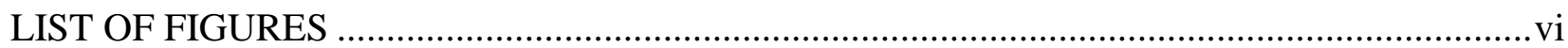

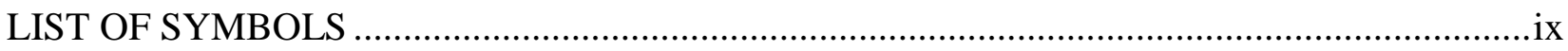

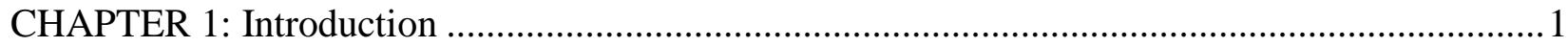

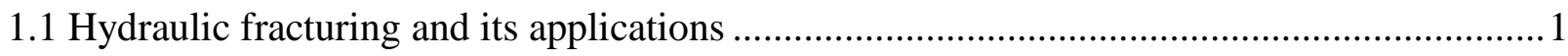

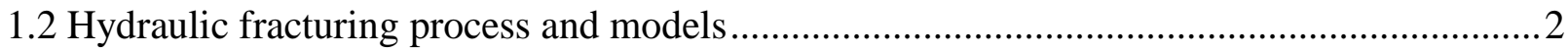

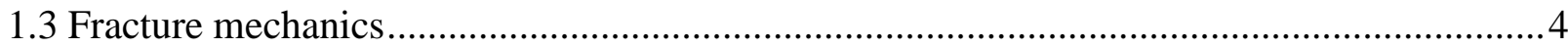

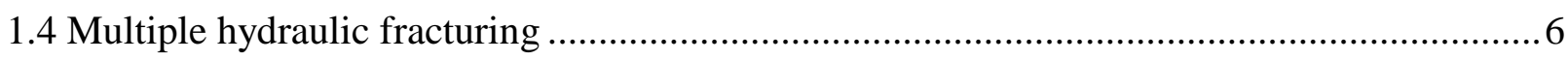

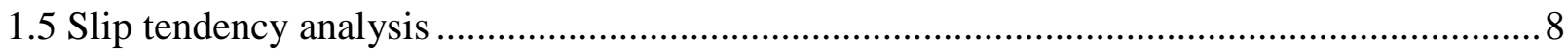

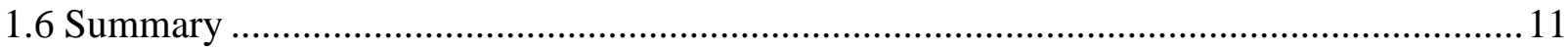

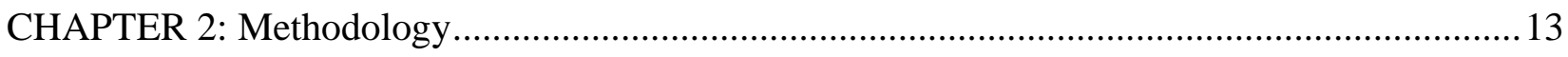

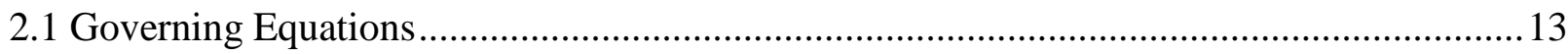

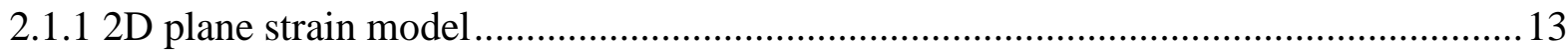

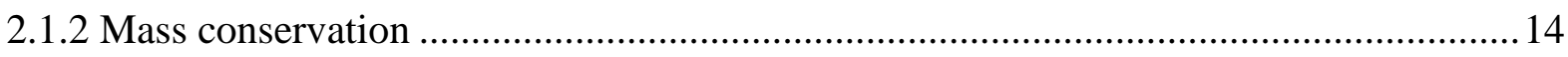

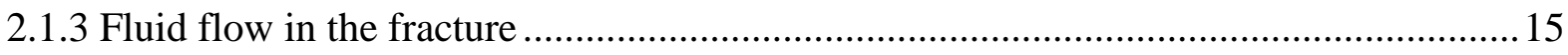

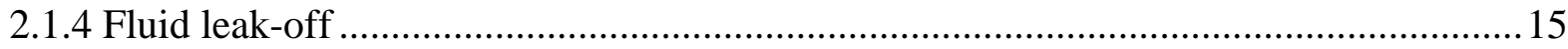

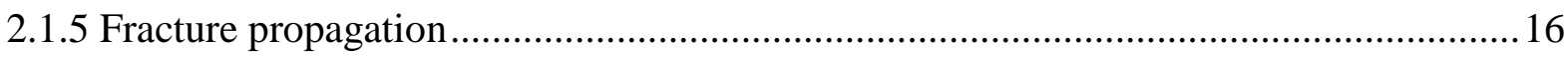

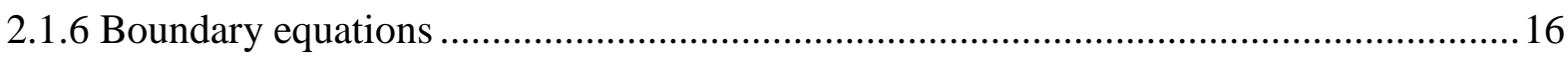

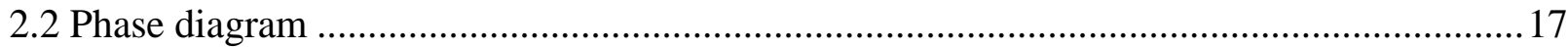

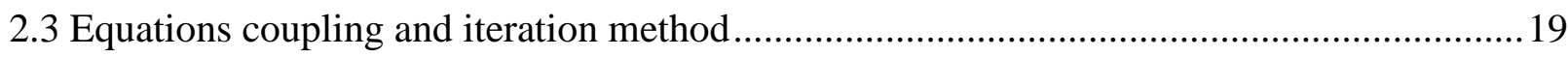

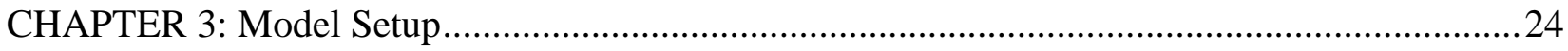

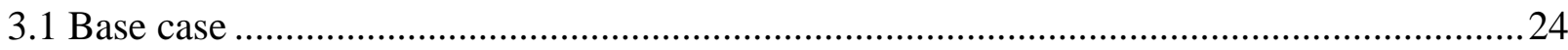

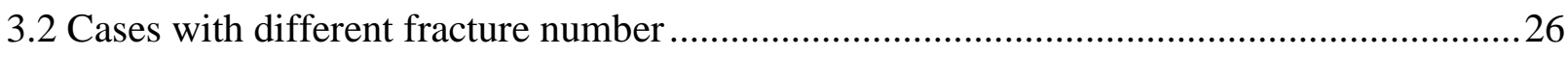

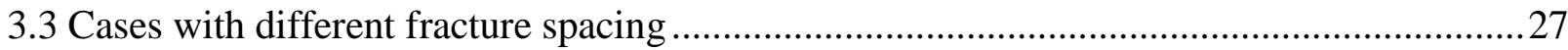

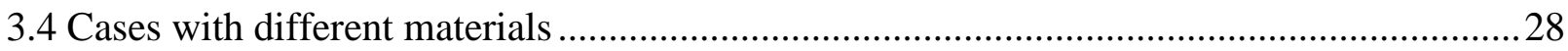

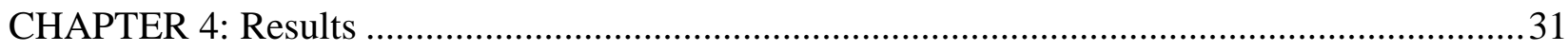

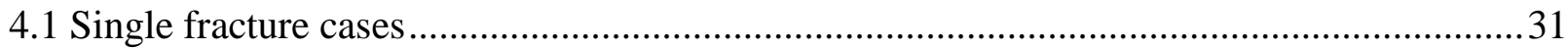

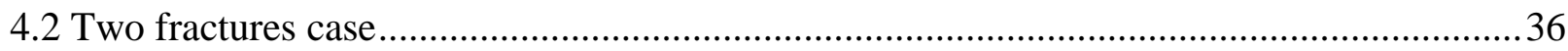


4.3 Effect of number of fractures ................................................................................ 38

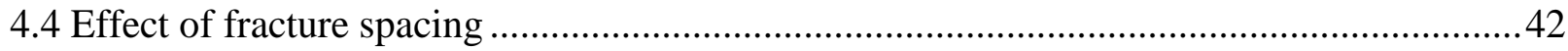

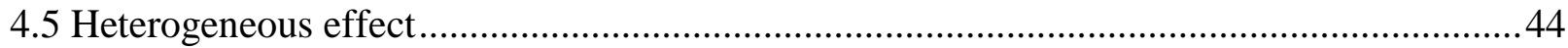

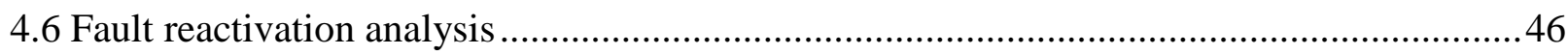

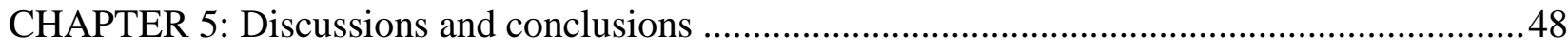

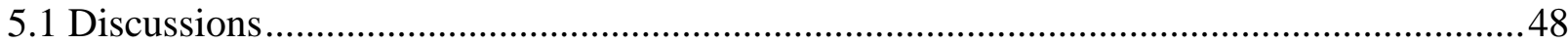

5.2 Conclusions and recommendations for future work .................................................49

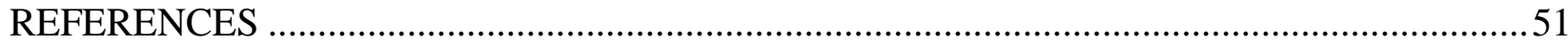




\section{LIST OF FIGURES}

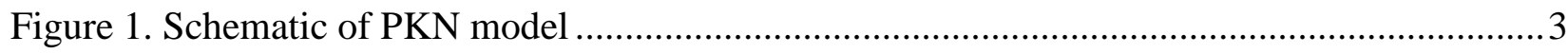

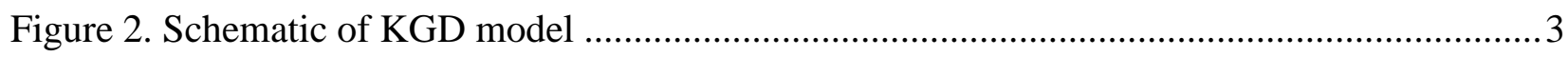

Figure 3. Schematic of Radial model...............................................................................

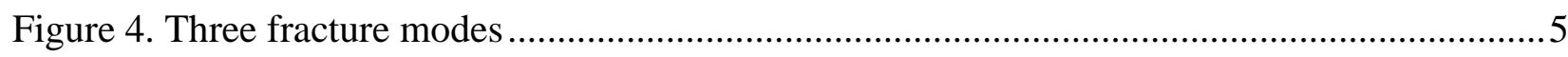

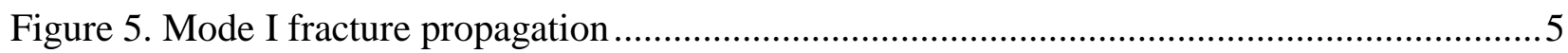

Figure 6. Fracture orientation deviation in sequential fracturing (Bunger, 2012) ..........................

Figure 7. Faulting systems predicted by Anderson's theory (courtesy GeoMechanics Intl. Inc.)....9

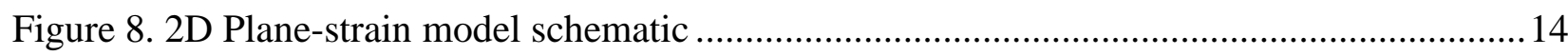

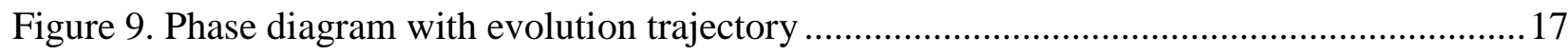

Figure 10. Domain for M-integral calculation (Bao et al. 2014) ................................................2 20

Figure 11. (a) Single fracture model with 100 elements on pre-defined fracture path (case 1). (b)

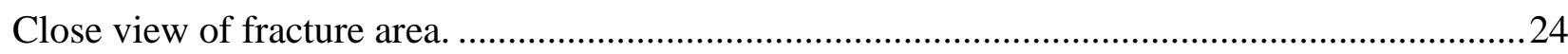

Figure 12. (a) Single fracture model with 200 elements on pre-defined fracture path (case 2). (b)

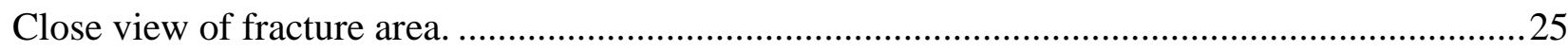

Figure 13. Close view of fracture area. (a) Single fracture model (case 1). (b) Two fractures model with $5 \mathrm{~m}$ spacing (case 3). (c) Three fractures model with $5 \mathrm{~m}$ spacing (case 4)............................27 Figure 14. Close view of fracture area in (a) Three fractures model with $5 \mathrm{~m}$ spacing (case 4). (b) Three fractures model with $10 \mathrm{~m}$ spacing (case 5). (c) Three fractures model with $15 \mathrm{~m}$ spacing

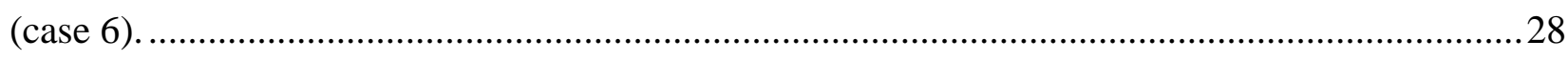

Figure 15. Illustration of composite reservoir model................................................................ 28

Figure 16. (a) Case 7 model with two materials. The boundary is far away from fracture. (b) Case

8 model with two materials. The boundary is close to the fracture. (c) Case 9 model with two

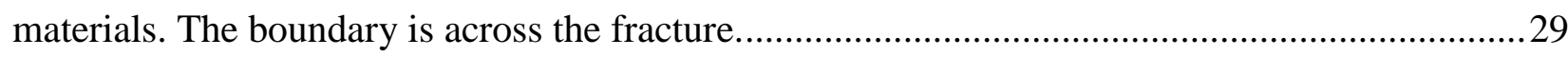

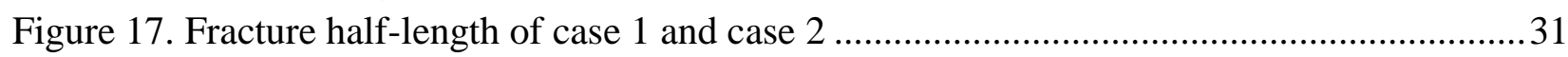

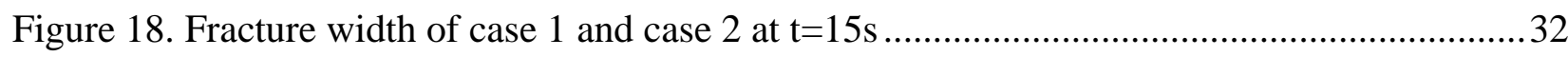

Figure 19. Fracture profile of case 1 at $\mathrm{t}=15 \mathrm{~s}$

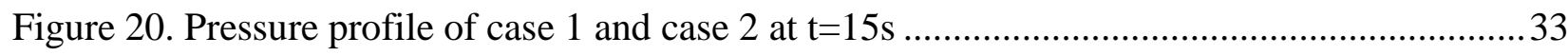

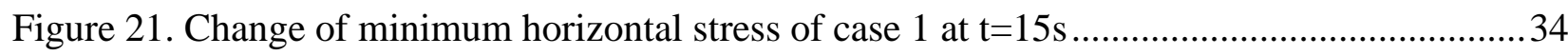

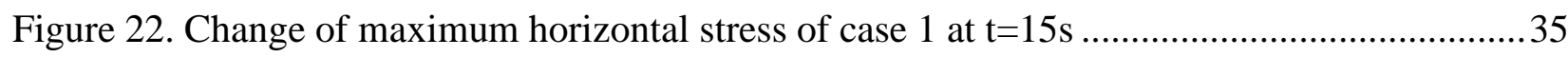

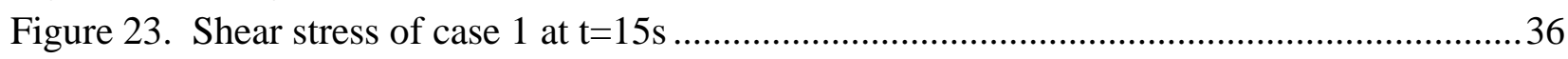

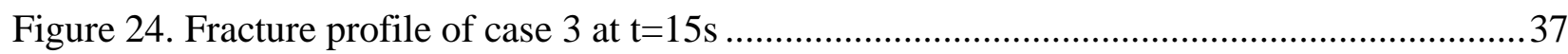

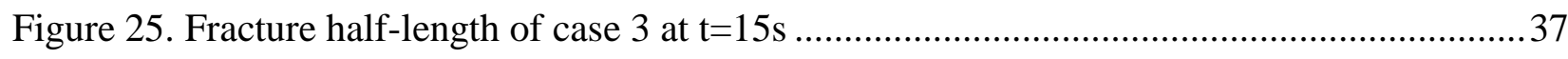

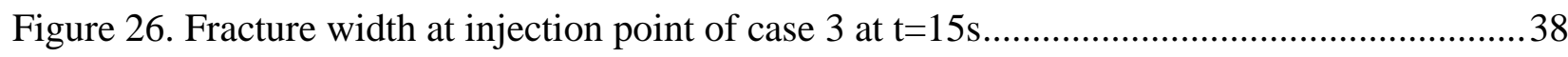

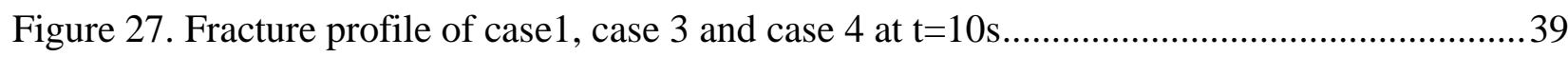

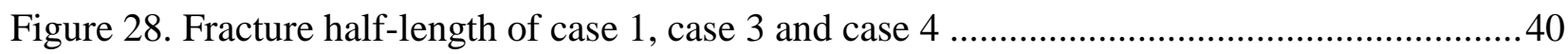

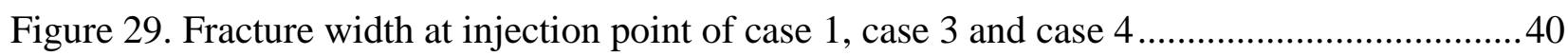

Figure 30. (a) Change of minimum horizontal stress of case 1 at $t=8 \mathrm{~s}$. (b) Change of minimum

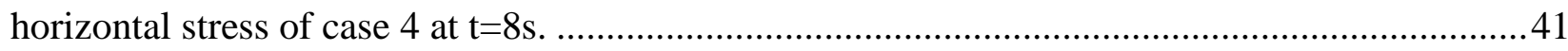

Figure 31. Change of maximum horizontal stress of case 4 at $t=8 \mathrm{~s}$.............................................4 


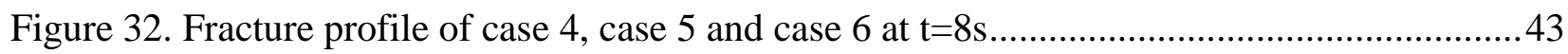

Figure 33. Fracture half-length of case 4, case 5 and case 6 ............................................43

Figure 34. Center fracture width at injection point of case 4, case 5 and case 6 ...................... 44

Figure 35. Fracture half-length of cases with modified Poisson's ratio ..................................... 45

Figure 36. Fracture half-length of cases with modified Young's modulus ................................ 45

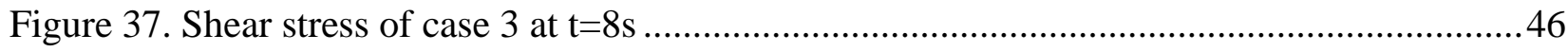

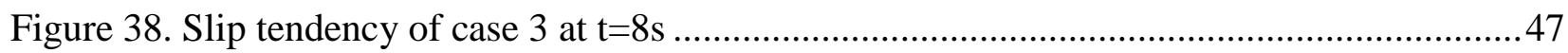




\section{LIST OF TABLES}

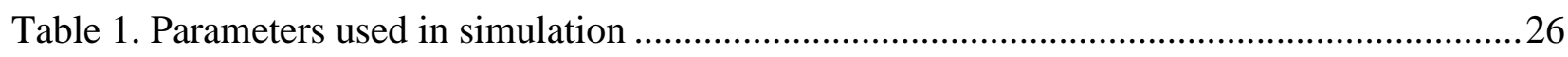

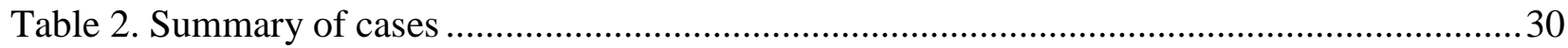




\section{LIST OF SYMBOLS}

\begin{tabular}{|c|c|}
\hline$\sigma_{0}$ & Confining stress \\
\hline$Q_{0}$ & Fluid injection rate \\
\hline$p_{f}$ & Fluid pressure \\
\hline$p$ & Net fluid pressure \\
\hline$\Delta p$ & Pressure increment \\
\hline$p_{0}$ & Initial nest fluid pressure \\
\hline$l(t)$ & Half fracture length at time step $t$ \\
\hline E & Young's modulus \\
\hline$v$ & Poisson's ratio \\
\hline$K_{I}$ & Stress intensity factor \\
\hline$K_{I C}$ & Toughness \\
\hline$\mu$ & Fluid dynamic viscosity \\
\hline$C_{l}$ & Leak-off coefficient \\
\hline$E^{\prime}$ & Plane strain modulus \\
\hline$K^{\prime}$ & Modified toughness \\
\hline$\mu^{\prime}$ & Modified fluid dynamic viscosity \\
\hline$C_{l}^{\prime}$ & Modified leak-off coefficient \\
\hline$w(x, t)$ & Fracture width at coordinate $\mathrm{x}$ and time step $\mathrm{t}$ \\
\hline$\Delta w$ & Width increment \\
\hline$t$ & Time \\
\hline$q$ & Flow rate \\
\hline$g$ & Leak-off rate \\
\hline$t_{0}(x)$ & Fracture tip arrival time \\
\hline$\tau$ & Shear stress \\
\hline$\varepsilon$ & Tolerance \\
\hline$S$ & Collection of boundary conditions \\
\hline$S_{0}$ & Cohesion strength \\
\hline$\sigma_{0}$ & Far field confining stress \\
\hline$Q_{0}$ & Fluid injection rate \\
\hline$p_{f}$ & Fluid pressure \\
\hline$p$ & Net fluid pressure \\
\hline$p_{0}$ & Initial nest fluid pressure \\
\hline$l(t)$ & Half fracture length at time step $t$ \\
\hline E & Young's modulus \\
\hline$v$ & Poisson's ratio \\
\hline$K_{I}$ & Stress intensity factor \\
\hline$K_{I C}$ & Toughness \\
\hline$\mu$ & Fluid dynamic viscosity \\
\hline$C_{l}$ & Leak-off coefficient \\
\hline
\end{tabular}


$\begin{array}{ll}E^{\prime} & \text { Plane strain modulus } \\ K^{\prime} & \text { Modified toughness } \\ \mu^{\prime} & \text { Modified fluid dynamic viscosity } \\ S_{H \min } & \text { Minimum horizontal stress } \\ S_{H \max } & \text { Maximum horizontal stress } \\ \sigma_{n} & \text { Normal stress } \\ \sigma_{1} & \text { First principle stress } \\ \sigma_{3} & \text { Principle stress } \\ \beta & \text { Angle between the normal direction of fault plane and the first principle direction } \\ T s & \text { Slip tendency } \\ K_{m} & \text { Dimensionless toughness in } M \text { scaling } \\ C_{m} & \text { Dimensionless leak-off coefficient } \\ \delta & \text { Kronecker delta } \\ E & \text { Pressure influence coefficient matrix }\end{array}$ 


\section{CHAPTER 1: Introduction}

\subsection{Hydraulic fracturing and its applications}

Hydraulic fracturing and horizontal drilling are safely unlocking vast U.S. reserves of oil and natural gas found in unconventional reservoirs with shale and other tight-rock formations. These two techniques have been employed in industry for many years to increase the productivity since the horizontal drilling can expose more of the source rock pay zone to the well and hydraulic fracturing can create high conductive pathway for oil and gas flow (Economides and Martin, 2007). By definition, hydraulic fracturing is the process by which a fracture initiates and propagates due to hydraulic loading (i.e., pressure) applied by a fluid inside the fracture (Ptolemy, 1952). The fluid flow in hydraulic fracturing process includes fluid and solid "proppant" transport and distribution. After flow back, the proppants keep induced fracture open resisting in-situ stresses, which provides a high conductive pathway for oil and gas flow from reservoirs to wellbore (Mader, 1989).

Different hydraulic fracturing examples and applications exist both in nature and industry. Magma-driven dykes (Lister, 1990; Spence, 1985) and fracture growth along glacier beds driven by water (Tsai and Rice, 2010) are usually considered as natural examples of hydraulic fracturing. In the industry, the first hydraulic fracturing treatment to stimulate well production dated back to 1947 in Kansas on a gas well in Hugoton field (Veatch, 1989). After that, hydraulic fracturing was extensively used in the petroleum industry to stimulate oil and gas wells to increase the productivity. Other common applications of hydraulic fracturing in industry include waste drill cuttings underground disposal (Moschovidis et al., 2000), heat production from geothermal reservoirs (Pine and Cundall, 1985) and the in-situ stresses measurement (Desroches and Thiercelin, 1993). 


\subsection{Hydraulic fracturing process and models}

Hydraulic fracturing generally starts with the creation of initial path by perforation. Then the wellbore is pumped with a viscous fluid into created finger-like holes. After that, the "pad" (clean fluid) is injected and followed by proppant (usually a suspension or slurry) injection. The operation time ranges from half an hour to a few hours depending on the designed fracture size and proppant volume. After these treatments, the pumping stops and the residual fracturing fluid will flow into the porous reservoir. The fracture surface will close due to far-filed confining stresses. A conductive path way will be formed for oil and gas flow due to proppant resistance.

There have been intensive efforts devoted to study reasonable hydraulic fracturing models since 1950s (Harrison et al., 1954; Howard and Fast, 1957; Crittendon, 1959). For two dimensional (2D) models, commonly used models include Perkins-Kern-Nordgren (PKN) model, KhristianovicGeertsma-de. Klerk (KGD) model and radial model (penny shape model). 3D models generally include pseudo-three-dimensional (P-3D) model and fully 3D model. Each model has been widely used in research and industry for prediction of hydraulic fracturing. In this study, 2D models and their characteristics will be mainly introduced.

In 1961, Perkins and Kern developed the PK model (Perkins and Kern, 1961). And later Nordgren updated to PKN model which included fluid loss based on PK model (Nordgren, 1972). The schematic of this model is shown in figure 1. In this model, the height is fixed as $\mathrm{H}$ and vertical and horizontal intersection is elliptic. This model is applicable for long fractures with limited height. 


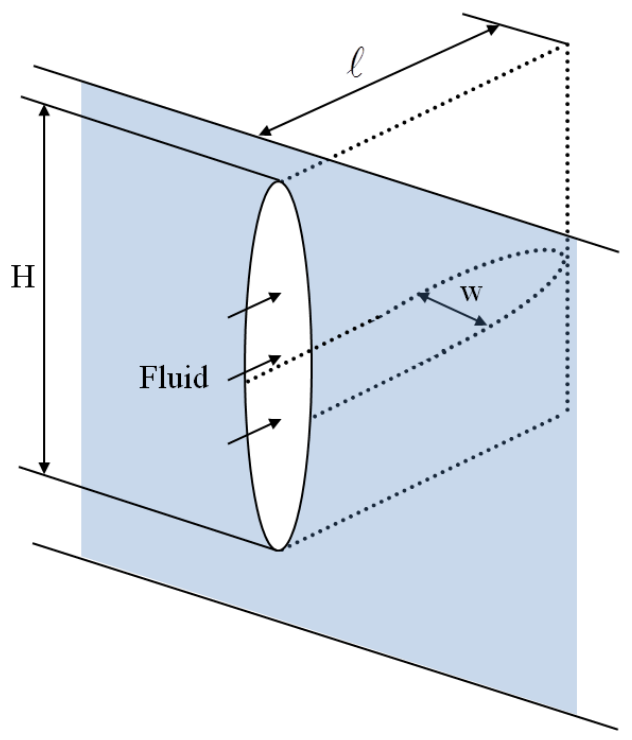

Figure 1. Schematic of PKN model

The second model "KGD model" was developed independently by Khristianovic and Zheltov (Khristianovic and Zheltov, 1955), and Geertsma and de Klerk (Geertsma and de Klerk, 1969). Figure 2 shows the schematic of KGD model. Compared to PKN model, it is height independent. So the plane strain assumption, which is height is very large compared to other dimensions, is applicable to horizontal sections in KGD model. The horizontal intersection is also elliptic. This model is applicable for fractures that are short when compared to their height.

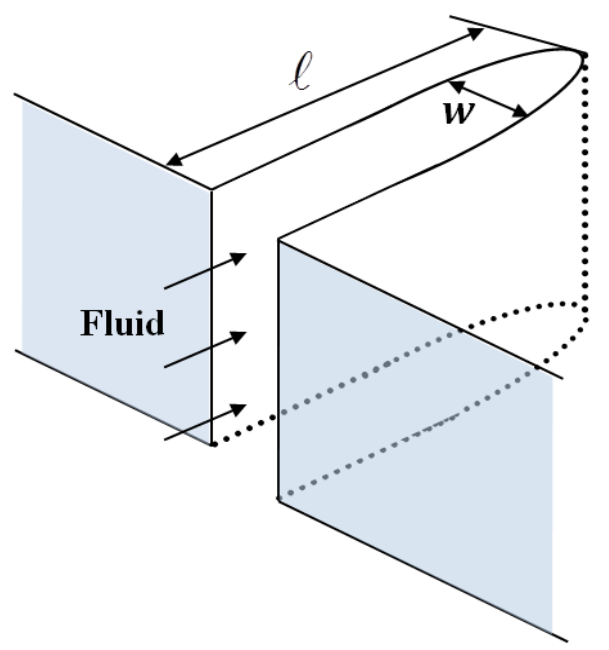

Figure 2. Schematic of KGD model 
The third model is radial model, which is also called "penny shape model". This model was studied by Sneddon (Sneddon, 1946) and Green (Green and Sneddon, 1950). Figure 3 shows the schematic of radial model. The hydraulic fracturing fluid is injected in the center of wellbore and then pumped to surrounding fractures. This model is applicable in homogeneous reservoir conditions where the injection region is practically a point source.

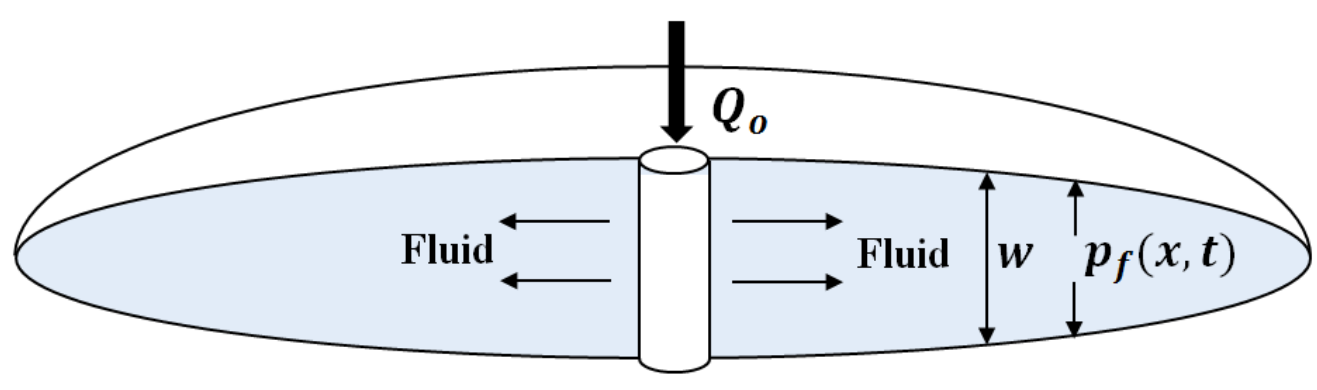

Figure 3. Schematic of Radial model

These 2D models are still used today in research and industry after extensive development and refinement. The importance of these $2 \mathrm{D}$ models is to make reasonable estimations rather than calculating precise geometry of hydraulic fractures. In this study, the two dimensional (2D) plane strain KGD model is selected for the geometry description and the fluid used in the model is assumed to be incompressible, laminar and Newtonian.

\subsection{Fracture mechanics}

There are three modes of fracture propagation when applied a force, which are opening, sliding and tearing as shown in figure 4. For mode I fracture opening, a tensile stress normal to the fracture plane is applied to propagate fracture. In this study, we consider the mode I opening for fracture propagation. 


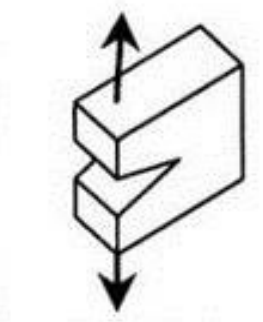

Mode I: Opening
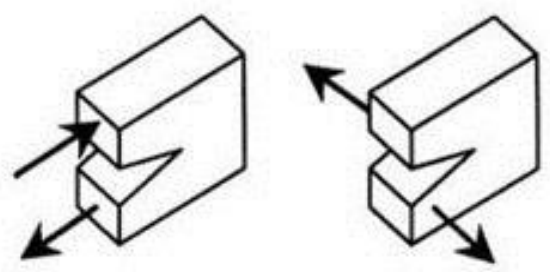

Mode II : Sliding Mode III: Tearing

Figure 4. Three fracture modes

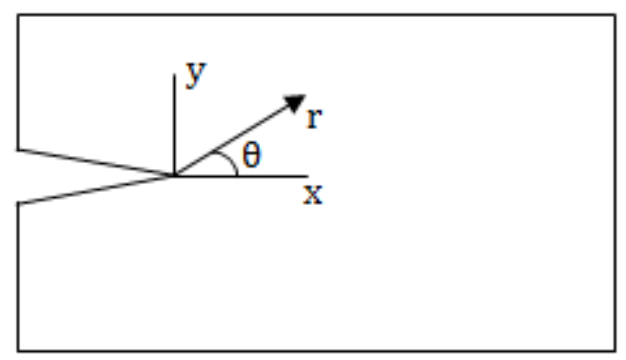

Figure 5. Mode I fracture propagation

The stress at the tip of the fracture for Mode I have following expressions:

$$
\begin{aligned}
& \sigma_{x}=\frac{K_{I}}{\sqrt{2 \pi r}}\left\{\cos \frac{\theta}{2}\left[1-\sin \frac{\theta}{2} \sin \frac{3 \theta}{2}\right]\right\} \\
& \sigma_{y}=\frac{K_{I}}{\sqrt{2 \pi r}}\left\{\cos \frac{\theta}{2}\left[1+\sin \frac{\theta}{2} \sin \frac{3 \theta}{2}\right]\right\}(-\pi \leq \theta \leq \pi)(1) \\
& \tau_{x y}=\frac{K_{I}}{\sqrt{2 \pi r}}\left\{\sin \frac{\theta}{2} \cos \frac{\theta}{2} \cos \frac{3 \theta}{2}\right\}
\end{aligned}
$$

Where $K_{I}$ is stress intensity factor for mode I and $\theta$ is angle between $x$ and $r$ as shown in figure 5 .

Based on the linear elasticity, the relationship between fracture width $w$ and net fluid pressure $p$ at any moment $t$ in the half space ( $\mathrm{x}>=0$ ) can be expressed as (Sneddon and Lowengrub, 1969) 


$$
w(x, t)=\frac{\pi}{4 E^{\prime}} \int_{l_{t}} \ln \left|\frac{\sqrt{l_{t}^{2}-x^{2}}+\sqrt{l_{t}^{2}-x_{1}^{2}}}{\sqrt{l_{t}^{2}-x^{2}}-\sqrt{l_{t}^{2}-x_{1}^{2}}}\right| p\left(x_{1}, t\right) d x_{1}
$$

Where $l(t)$ is the fracture half-length at time $t$ and $E^{\prime}$ is plane strain modulus.

\subsection{Multiple hydraulic fracturing}

In multistage hydraulic fracturing of horizontal wells, multiple fractures are created in one cluster in any single stage. It is important to create as many effective fractures as possible in a line to extract hydrocarbons from the reservoir. When two or more fractures are created, the mechanical interactions between them will affect their geometries. How to place them to generate maximum contact surface becomes a critical issue. Parameters, such as the number of fractures, fracture spacing and fluid flow rate, should be determined and optimized before operations.

Intensive efforts have been devoted in investigating the multiple hydraulic fractures interaction to achieve maximum contact surface area between formation and production well to maximize the production. Sequential fracturing, which is the growing fracture interacting with pre-existing fractures, showed that the orientation and magnitude of fracture can be affected by previous fractures (Fisher, 2004).

Figure 6 shows an example of fracture orientation deviation in sequential fracturing. HF1 is a preexisting fracture and HF2 is the following fracture. Due to stress alteration induced by HF1, HF2 deviates outside of HF1 instead of parallel to HF1 as shown. For multiple sequential hydraulic fracturing, the final fracture network will be very complex due to interactions with existing fractures. The examples of fracture network of Barnett Shale were given in Fisher's paper and growing hydraulic fractures clearly interacted with existing fractures in the reservoir. 


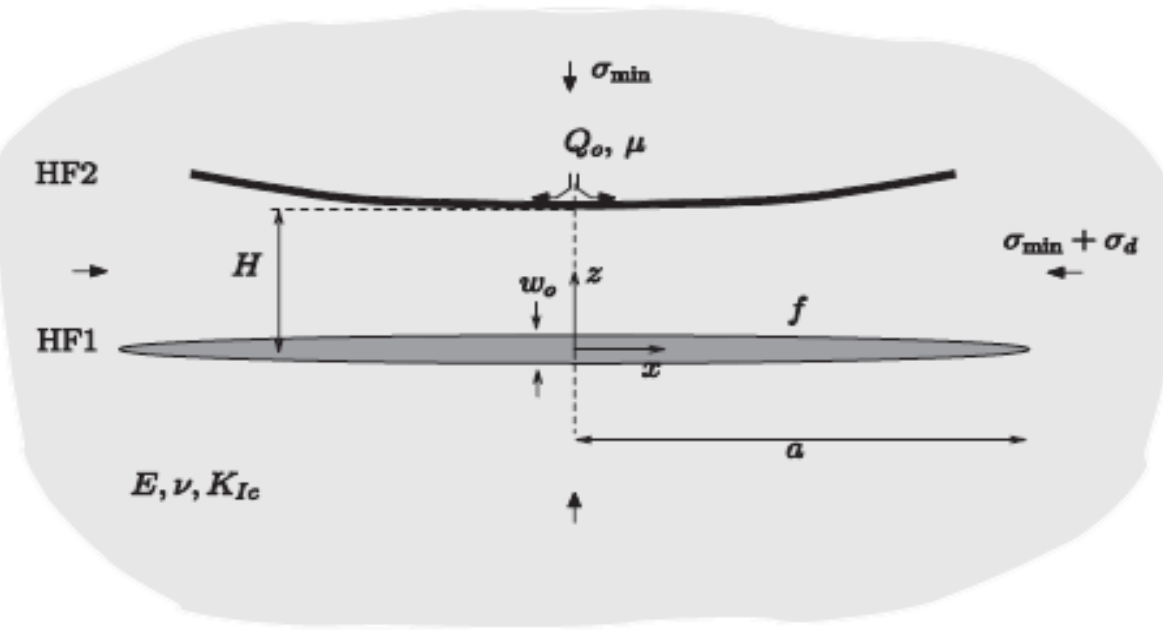

Figure 6. Fracture orientation deviation in sequential fracturing (Bunger, 2012)

Olson and Dahi-Taleghani, 2009, used the boundary element numerical model to quantify the mechanical interaction between fractures for fracture propagation. The model is suitable for multiple, non-planar, pseudo-3d fractures. They demonstrated how induced stresses around pressurized fractures can locally alter principal stress directions such that hydraulic fractures are not always propagating perpendicular to remote, in-situ $S_{\mathrm{hmin}}$ direction. Their study show that fracture complexity is mainly influenced by the net pressure where higher net pressure tends to generate greater complexity.

These achievements in sequential fracturing can be considered in simulation of simultaneous multiple hydraulic fracturing. Bunger, 2014, introduced three important factors to determine the propensity for simultaneous multiple hydraulic fractures propagation. These factors are hydraulic fracture geometry (PKN, KGD or radial model), perforation pressure loss and dissipation of energy through viscous fluid flow. Based on reservoir conditions, such as toughness, Young's modulus and Poisson's ratio of medium, a method of determining neglecting curving (fracture deflection by pre-existing fractures) was proposed. This approach provides us a useful tool to determine whether sufficient conditions are satisfied to neglect curving effect in engineering applications. 
Cheng, 2012 and 2013, used the boundary element model based on displacement discontinuity method to investigate the interactions of multiple fractures. She found that the magnitude of mechanical interactions of fractures is closely related to number of fractures and fracture spacing. Increasing the number of perforation clusters in one stage does not guarantee increasing of the production. Because mechanical interactions between edge fractures and center fracture inhibited the width growth, which decreased the overall fracture area. Hence that might not help to increase the production. In order to reach the maximum fracture efficiency, the optimal fracture number and spacing should be achieved under specific conditions.

Morrill, 2012, discussed different parameters affecting multiple hydraulic fracturing, such as Biot's constant, Young's modulus, Poisson's ratio, and horizontal stress ratio. He recommended that the most important parameter for determining the optimal fracture spacing, which is minimum fracture spacing without interaction, is the ratio of maximum horizontal stress and minimum horizontal stress. His conclusion was based on sensitivity analysis on different parameters mentioned above under certain conditions.

Here we are using the most sophisticated finite element model simulator HFWVU developed by our group to investigate parameters influencing multiple hydraulic fracturing and further determine possible fault reactivation zones during dynamic hydraulic fracturing. Sensitivity analysis with different fracture number, fracture spacing and rock properties will be simulated. Fault reactivation zones will be determined by using slip tendency analysis with geometry and stress profiles. This study provides us the advanced understanding of multiple hydraulic fracturing and helps us optimize multiple hydraulic fracturing operations.

\subsection{Slip tendency analysis}

In-situ stresses alteration induced by hydraulic fracturing may reactivate the surrounding faults or discontinuities. A better understanding of fault mechanics and in-situ stresses change is a 
necessity to investigate the possible fault reactivation zones during hydraulic fracturing in case of operation failure and potential induced microseismicity events.
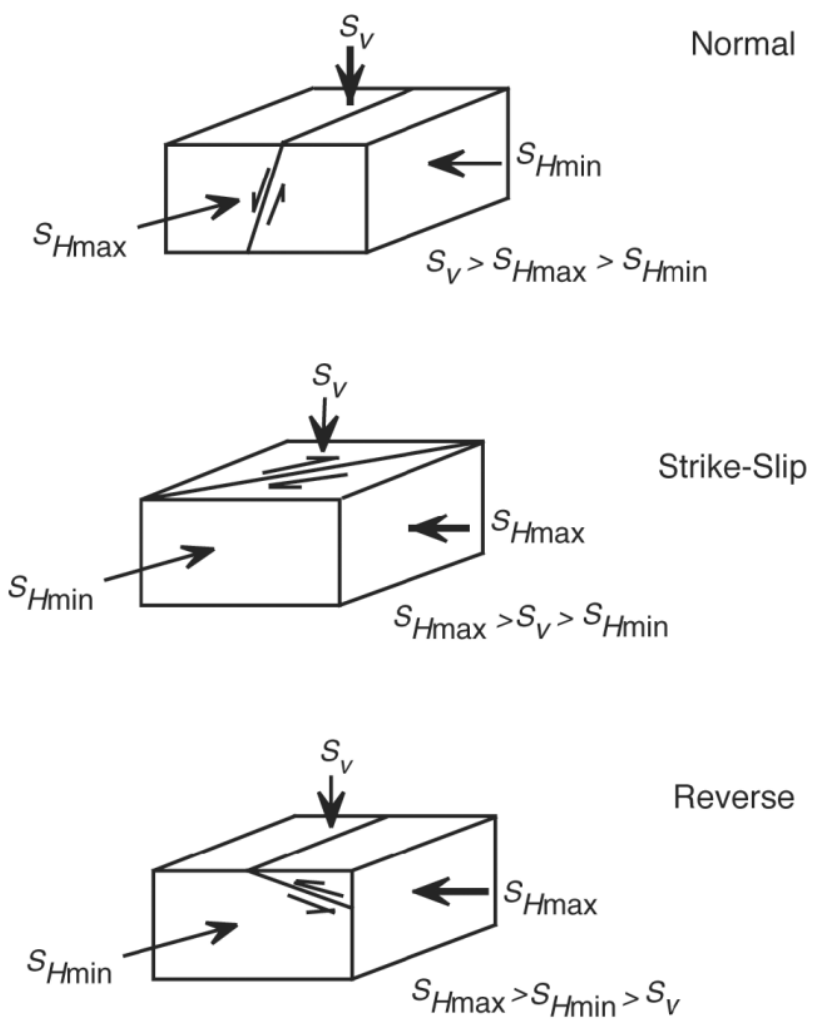

Figure 7. Faulting systems predicted by Anderson's theory (courtesy GeoMechanics Intl. Inc.). There are three types of faulting system introduced by Anderson's theory, which are normal faulting, strike-slip faulting and reverse faulting (Van der Pluijm and Marshak, 2004). The schematic of these faulting systems are shown in figure 7. The strike-slip faulting system will be considered in this study, which $\sigma_{1}$ and $\sigma_{3}$ are in horizontal plane and sliding happens perpendicular to vertical stress.

When the shear stress overcomes a critical value, the frictional sliding can be expected to occur on a fault plane. This relationship is known as the Coulomb criterion (Jaeger, et al. 2007),

$$
\tau=S_{0}+\mu \sigma_{\mathrm{n}}(3)
$$


Where $S_{0}$ is called cohesion strength, $\tau$ is the shear stress on the fault plane, $\sigma_{n}$ is the effective normal stress and $\mu$ is the coefficient of static friction. The shear and normal stresses that acting on an arbitrary plane with $\beta$ angle between the normal direction of fault plane and the first principle direction have following expressions:

$$
\begin{gathered}
\sigma_{n(\beta)}=\frac{1}{2}\left(\sigma_{1}+\sigma_{3}\right)+\frac{1}{2}\left(\sigma_{1}-\sigma_{3}\right) \cos 2 \beta \\
\tau_{\beta}=\frac{1}{2}\left(\sigma_{1}-\sigma_{3}\right) \sin 2 \beta
\end{gathered}
$$

Based on the Coulomb criterion, slip tendency $T s$ can be defined to describe stability or failure acting on the plane of weakness (Lisle and Srivastava, 2004 and Morris et al., 1996). The slip tendency on an arbitrarily oriented plane at an angle $\beta$ to the first principle stress is defined as (Morris et al., 1996),

$$
\mathrm{T}_{S}=\frac{\tau_{(\beta)}-S_{0}}{\sigma_{\mathrm{n}(\beta)}}
$$

In this study, $S_{0}$ is assumed to be zero, so it becomes

$$
\mathrm{T}_{S}=\frac{\tau_{(\beta)}}{\sigma_{\mathrm{n}(\beta)}}(6)
$$

Based on equation (4) and (6), the slip tendency becomes

$$
\mathrm{T}_{S}=\frac{\left(\sigma_{1}-\sigma_{3}\right) \sin 2 \beta}{\left(\sigma_{1}+\sigma_{3}\right)+\left(\sigma_{1}-\sigma_{3}\right) \cos 2 \beta}
$$

In order to calculate the maximum slip tendency on this plane, we take derivation of equation (7) with respect to $2 \beta$. Then the maximum slip tendency can be obtained. It has the following expression, 


$$
\begin{gathered}
\mathrm{T}_{S}=\frac{\frac{\left(\sigma_{1}-\sigma_{3}\right)}{2}}{\sqrt{\left(\frac{\sigma_{1}+\sigma_{3}}{2}\right)^{2}-\left(\frac{\sigma_{1}-\sigma_{3}}{2}\right)^{2}}} \\
\sin 2 \beta=-\frac{\left(\sigma_{1}-\sigma_{3}\right)}{\left(\sigma_{1}+\sigma_{3}\right)}
\end{gathered}
$$

Equation (8) can be used to obtain the maximum slip tendency to identify possible fault reactivation zones during hydraulic fracturing. The value of $\beta$ is also given from $\sin 2 \beta$ when it meets the maximum slip tendency.

\subsection{Summary}

In this introduction chapter, the hydraulic fracture processes and its applications were introduced first. Then the commonly used 2D hydraulic fracture models and their characteristics were described. Research work in sequential and simultaneous multiple hydraulic fracturing was reviewed to outline the research objectives for this thesis. The introduction of slip tendency analysis provides the theoretical basis for determining possible fault reactivation zones.

In the chapter 2, the methodology of multiple hydraulic fracture modeling is given. The governing equations include mass conservation, momentum conservation, fluid flow in the fracture and leakoff. The coupling and discretization of these equations employs the finite element method. Based on the energy dissipation and fluid storage mechanisms, the phase diagram is derived.

In the chapter 3, different cases are constructed. The corresponding models for consideration of number of fractures, fracture spacing and number of materials are built. Initial and boundary conditions are also given for each case. 
Chapter 4 shows the results of modeled cases in chapter 3. First we show results of single fracture case and validate the simulation program. Sensitivity analysis results of each parameter are given including fracture number, fracture spacing and heterogeneities. The stress analysis gives us further understanding of mechanical interaction between fractures. Finally the slip tendency analysis is employed to identify possible reactivation zones during hydraulic fracturing.

Chapter 5 summarizes works done in previous chapters and give information regarding the future research direction. The results in this study are obtained for example conditions but the simulation can be applied to general cases. 


\section{CHAPTER 2: Methodology}

\subsection{Governing Equations}

Hydraulic fracturing is a very complicated process to model even in its most basic form (Adachi et al. 2007). At least three processes are coupled which are mechanical deformation induced by fluid pressure on the fracture surface, fluid flow in the fracture and fracture propagation. Each process can be described by corresponding underlying mechanical theory and characterized by governing equation. The deformation is usually modeled by using linear elasticity theory. The fluid flow is characterized by lubrication theory. And the linear elastic fracture mechanics (LEFM) theory is used as criterion for fracture propagation, which is the fracture propagates if the

stress intensity factor at the tip matches the rock toughness. Besides these three processes, the fluid leak-off to surrounding medium is also considered in many cases since $100 \%$ of efficiency to fracturing opening is not possible in a porous media (Devloo et al. 2006). Fluid lag is referred to a gap zone between the fluid front and fracture tip. As the fracture evolves, the fluid lag tends to gradually disappear, especially under conditions of high confining stress (Lecampion and Detournay, 2007). In this thesis work, the leak-off is considered and fluid lag effect is neglected.

\subsubsection{D plane strain model}

The physical process of hydraulic fracturing is very complicated since it involves both fluid and solid part. The fracture propagates along the solid medium that driven by pressurized fluid. The mathematical equations can be derived based on mass conservation, lubrication theory (Poiseuille's law), leak-off control and fracture propagation criterion.

The model we choose to use for hydraulic fracturing in this study is two dimensional (2D) plane strain KGD model. The schematic of this model is shown in figure 8. The fluid flow with flow rate of $Q_{0}$ is injected in the center and then flow to surrounding fractures. The far field confining stress $\sigma_{0}$ is applied surrounding the fracture. $l(t)$ is fracture half-length at time step $t$ and $w(x, t)$ is fracture width at $x$ and time step $t$. 


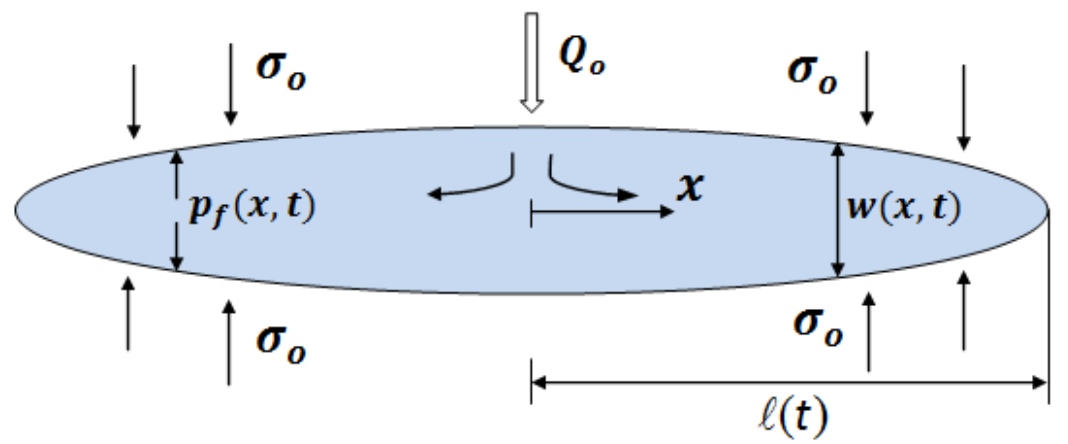

Figure 8. 2D Plane-strain model schematic

In this figure, $p_{f}$ is fluid pressure on the fracture surface and $p$ is the net fluid pressure related to $p_{f}$ and $\sigma_{0}$, by the following expression:

$$
p(\mathrm{x}, \mathrm{t})=p_{f}(\mathrm{x}, \mathrm{t})-\sigma_{o}(\mathrm{x})
$$

As shown in figure 8 , the model is symmetric at $x=0$. Hence we will only consider half plane in the future. The fracture propagation will be characterized by Young's Modulus $E$, Poisson's ratio $v$ and rock toughness $K_{I C}$. Other parameters used in the equations are fluid dynamic viscosity $\mu$ and leak-off coefficient $C_{l}$. For the purpose of convenience, the following group of parameters is used in the future expressions,

$$
\mathrm{E}^{\prime}=\frac{\mathrm{E}}{1-\mathrm{v}^{2}}, \mu^{\prime}=12 \mu, \mathrm{C}_{\mathrm{l}}^{\prime}=2 \mathrm{C}_{\mathrm{l}}, \mathrm{K}^{\prime}=\frac{8}{\sqrt{2 \pi}} \mathrm{K}_{\mathrm{IC}} \text { (10) }
$$

$E^{\prime}$ is plane strain modulus. $\mu^{\prime}, C_{l}^{\prime}$ and $K^{\prime}$ are referred as modified viscosity, leak-off coefficient and toughness, respectively. These parameters will be used in the governing equations in the following sections.

\subsubsection{Mass conservation}

In the case of incompressible fluid flow within the fracture, the fluid mass conservation law can be written as (Boone and Ingraffea, 1990),

$$
\frac{\partial w}{\partial t}+\frac{\partial q}{\partial x}+g=0
$$


Where $q$ is fluid flux and $g$ is the leak-off term which will be characterized in equation (15). If we integrate above equation with respect to $x$, it becomes:

$$
\frac{\partial}{\partial t} \int_{x}^{\ell} w d x+\int_{x}^{\ell} g d x=q
$$

And taking the second time integration leads to:

$$
2 \int_{0}^{\ell} w d x+2 \int_{0}^{t} \int_{0}^{\ell\left(t^{\prime}\right)} g d x d t^{\prime}=Q_{o} t
$$

Equation (13) defines the global fluid continuity equation in whole domain.

\subsubsection{Fluid flow in the fracture}

Due to fracture geometry characteristic, in which the fracture width (millimeters) is much smaller than the fracture length (hundreds to thousands meters), lubrication theory can be used to describe the fluid flow inside the fracture (Batchelor, 1967). It is also governed by Poiseuille's law that defines the fluid flow as follow:

$$
q=-\frac{w^{3}}{\mu^{\prime}} \frac{\partial p_{f}}{\partial x}
$$

Where $p_{f}$ is fluid pressure at the fracture surface and $\mu^{\prime}$ is characterized viscosity in equation (10).

\subsubsection{Fluid leak-off}

Fluid leaking off to surrounding media is also considered in some circumstances. Carter's leak-off model is used to describe this phenomenon (Carter, 1957). The expression is defined as follow:

$$
g(x, t)=\frac{C_{1}^{\prime}}{\sqrt{t-t_{0}(x)}}, t>t_{0}(x)
$$


Where $C_{l}^{\prime}$ is modified leak-off coefficient as described in equation (10) and $t_{0}(x)$ is time of fracture tip arrives at $x$. This equation does not consider fluid spurt-loss to the porous media.

\subsubsection{Fracture propagation}

In the simulation, since only mode I tensile opening of fracture propagation is considered, the propagation criterion is then defined as:

$$
K_{I} \geq K_{I C}(16)
$$

Where $K_{I}$ is the stress intensity factor (SIF) of mode I opening for the fracture and $K_{I C}$ is rock toughness. As long as the above criterion meets, the fracture will propagate to the next element. To ensure the time step is properly selected, $K_{I}$ should also satisfy the following criterion:

$$
K_{I} \leq(1+\varepsilon) K_{I C}
$$

Where $\varepsilon$ is the allowable tolerance for SIF. In our numerical simulation, $\varepsilon$ is taken as 0.01 . The detailed calculation of $K_{I}$ can be found in later section with finite element method.

\subsubsection{Boundary equations}

In the model, the boundary conditions for fluid flow are

$$
\mathrm{q}(0)=\frac{\mathrm{Q}_{0}}{2}, \mathrm{q}(\mathrm{l})=0
$$

The first boundary condition describes the symmetry of the fracture and the second boundary condition implies zero fracture width at the tip.

The coupling of governing equations employs finite element method and equations will be discretized. The Newton-Raphson method is used to solve system of linear equations in finite 
element using iteration. Detailed coupling procedure and numerical issues can be found in the section 2.3.

\subsection{Phase diagram}

Based on the information of fluid storage and energy consumption in hydraulic fracturing, different hydraulic fracturing regimes can be defined that has been shown as a phase diagram in figure 9. There are two competing energy dissipation mechanisms, which are viscosity energy dissipation $(\mu)$ for fluid flow and toughness energy dissipation $(K)$ for fracture propagation. There are also two competing fluid storage mechanisms, which are fluid storage in the fracture and fluid leak-off $\left(C_{l}\right)$ to the porous media.

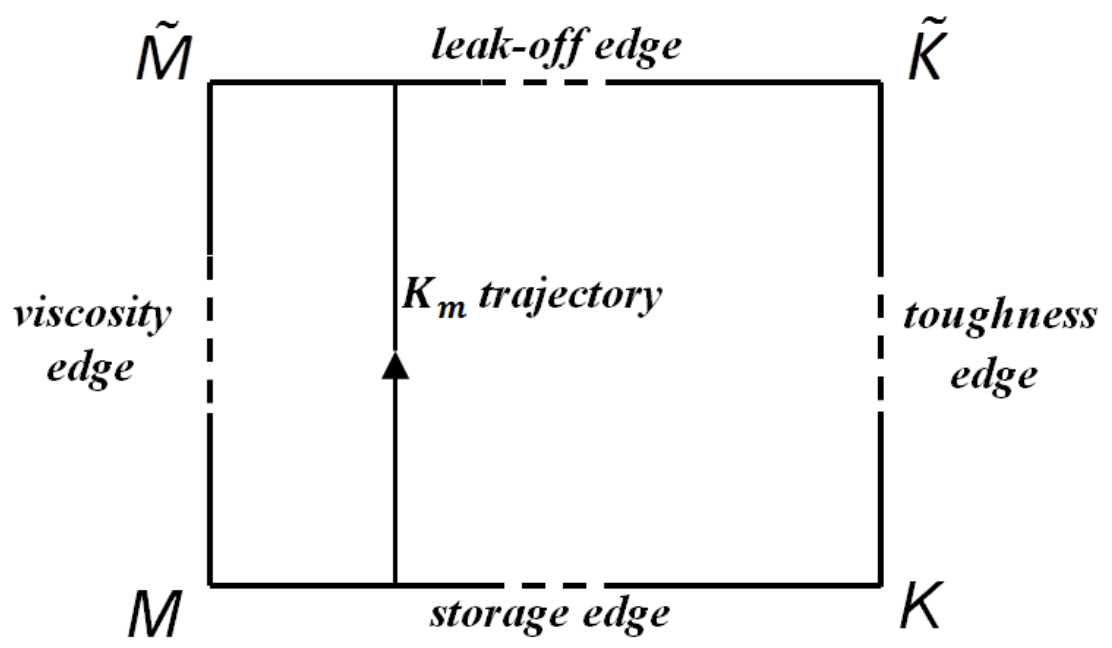

Figure 9. Phase diagram with evolution trajectory

In the phase diagram, there are four vertices and four edges. Four edges are viscosity dominated, leak-off dominated, storage dominated and toughness dominated. Each edge and vertex represents different physical meaning or process. The followings are the physical process that corresponding to different edges. 
In the $M K$ edge (storage edge), it represents the fracture is propagating in an impermeable medium where the leak off is zero.

In the $\tilde{M} \tilde{K}$ edge (leak-off edge), it means most injected fluid leaks into the rock during hydraulic fracturing.

In the $M \tilde{M}$ edge (viscosity edge), it represents the fracture propagates along a pre-existing discontinuity.

In the $K \tilde{K}$ edge (toughness edge), it represents the fracturing fluid has zero fluid viscosity and all energy is used for propagation.

Physical meaning or process of each vertex can be obtained by combining neighboring edges. For instance, $K$ vertex in the phase diagram represents the fracture propagation energy is consumed by propagation (toughness) and fluid is stored in the fracture. In this regime, there is no leaking-off to surrounding media and viscosity of fluid is assumed zero. The same situations can be applied to other vertices.

Note that there is a $K_{m}$ trajectory from storage edge to leak-off edge in the left part of phase diagram. This trajectory represents a typical hydraulic fracturing process. The physical process is hydraulic fracturing starts with small leak-off and energy mainly consumed by fluid transport in the early stage. Then gradually most fluid leak to surrounding media and energy is mainly consumed by fracture propagation. In this phase diagram, it starts with specific $K_{m}$ (near $\mathrm{M}$ vertex) and evolves to leak-off $\tilde{M} \tilde{K}$ edge along the $K_{m}$ trajectory.

In order to quantify these regimes in the phase diagram, dimensionless parameters are defined. The analytical solutions depend on hydraulic fracturing regimes that can be characterized using $K_{m}$ and $C_{m}$, which are defined as follows: 


$$
\begin{aligned}
& K_{m}=\frac{K^{\prime}}{E^{\prime}}\left(\frac{E^{\prime}}{\mu^{\prime} Q_{0}}\right)^{\frac{1}{4}} \\
& C_{m}=C^{\prime}\left(\frac{E^{\prime} t}{\mu^{\prime} Q_{0}^{3}}\right)^{\frac{1}{6}}
\end{aligned}
$$

These two parameters can indicate the energy dissipation regime and the fluid storage regime during hydraulic fracturing in the phase diagram. There have been different analytical solutions developed by researchers depending on the fracturing regimes (Garagash, 2006; Lecampion and Detournay, 2007; Garagash et al., 2011). HFWVU simulator developed in our group can be used to simulate hydraulic fracturing in all different regimes in the phase diagram. This has been confirmed by comparison of simulation results with analytical solutions in different fracturing regimes (Bao et al., 2014). So this thesis work is to expand the investigation of hydraulic fracturing from single fracture case to multiple fractures case in heterogeneous conditions. The following section briefly introduces the coupling of equations and iteration method used in the program. More details can be found at Bao et al. 2014.

\subsection{Equations coupling and iteration method}

For fracture propagation, the M-Integral method (Yau et al., 1980) is used to calculate $K_{I}$. The expression is

$$
K_{I}=\frac{E}{2\left(1-v^{2}\right)}\left\{\int_{D}\left[\sigma_{i j} \frac{\partial u_{i}^{a}}{\partial x_{1}}+\sigma_{i j}^{a} \frac{\partial u_{i}}{\partial x_{1}}-\sigma_{m n}^{a} \varepsilon_{m n} \delta_{1 j}\right] \frac{\partial \chi}{\partial x_{j}} d S-\int_{S_{e}} \chi p \frac{\partial u_{i}^{a}}{\partial x_{1}} d L\right\}
$$

Where domain $\mathrm{D}$ is a set of elements around the fracture tip in the discretized finite element model. $S_{e}$ is a set of edges of the finite elements in domain D and these edges coincide with the fracture surface as shown in figure 10 with dashed line. $\sigma_{i j}$ is the stress field, $x_{j}(j=1,2)$ is the local coordinate, $\mu_{i}(i=1,2)$ is the displacement field, $\delta$ is the Kronecker delta, $\chi$ is a scalar field, $\varepsilon_{m n}$ is the strain field, $\sigma_{i j}^{a}$ and $\mu_{i}^{a}$ are the auxiliary stress and displacement field, respectively. Einstein summation convention is used for repeated indices in equation (20). 


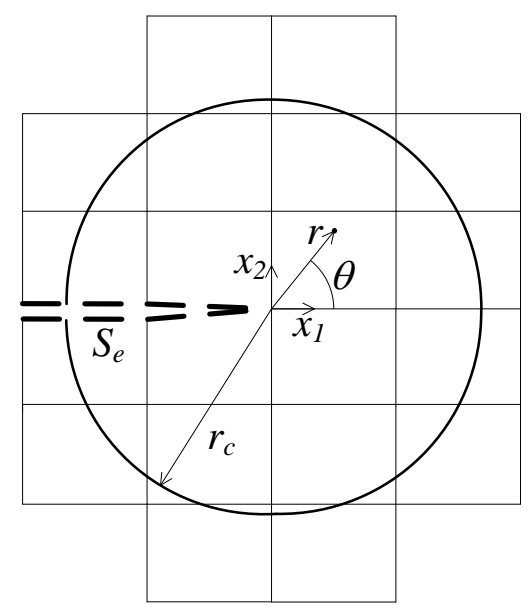

Figure 10. Domain for M-integral calculation (Bao et al. 2014)

The analytical solutions of the auxiliary stress and displacement field have the following expressions,

$$
\begin{aligned}
& u_{1}^{a}=\frac{1}{2 G} \sqrt{\frac{r}{2 \pi}}\left[\cos \frac{\theta}{2}(\kappa-\cos \theta)\right] \\
& u_{2}^{a}=\frac{1}{2 G} \sqrt{\frac{r}{2 \pi}}\left[\sin \frac{\theta}{2}(\kappa-\cos \theta)\right]
\end{aligned}
$$

Where $\mathrm{r}$ and $\theta$ is the local polar coordinate as shown in figure $10 . \mathrm{G}$ is the shear modulus and $\kappa$ is the Kosolov's constant and it equals $3-4 v$ in plane strain model. The auxiliary stress is (Paris and Sih, 1965)

$$
\begin{aligned}
& \sigma_{11}^{a}=\frac{1}{\sqrt{2 \pi r}}\left\{\cos \frac{\theta}{2}\left[1-\sin \frac{\theta}{2} \sin \frac{3 \theta}{2}\right]\right\} \\
& \sigma_{22}^{a}=\frac{1}{\sqrt{2 \pi r}}\left\{\cos \frac{\theta}{2}\left[1+\sin \frac{\theta}{2} \sin \frac{3 \theta}{2}\right]\right\}(-\pi \leq \theta \leq \pi) \\
& \sigma_{12}^{a}=\sigma_{21}^{a}=\frac{1}{\sqrt{2 \pi r}}\left\{\sin \frac{\theta}{2} \cos \frac{\theta}{2} \cos \frac{3 \theta}{2}\right\}
\end{aligned}
$$

After we calculate $K_{I}$ and meet the fracture propagation criterion in equation (16), the proper time step can be chosen. Then based on equation (2) developed earlier by Sneddon and Lowengrub, 1969, finite element discretization of the relationship between $w$ and $p$ can be derived and expressed as follow: 


$$
\Delta w_{i}=\sum_{j} E_{i j}\left(\Delta p_{j}\right)
$$

Where $\Delta w_{i}$ is width increment at point $i$ and $\Delta p_{j}$ is pressure increment at point $j$. The physical meaning of $E_{i j}$ is the fracture width at point $i$ induced by unit pressure applied at point $j$ within the fracture. The matrix form of above equation is

$$
\Delta w=E \Delta p(24)
$$

Due to its physical meaning, $E$ is named as pressure influence coefficient matrix. This matrix can be calculated by solving a series of finite element equations. According to principle of variation, equation (11) with any test function $\delta p$ leads to its weak form

$$
\int_{\ell}\left[-\nabla(\delta p) \cdot q+(\delta p) \frac{\partial w}{\partial t}+(\delta p) g\right] d \ell+\left.\delta p\left(q \cdot n_{1}\right)\right|_{s}=0
$$

Where $S$ is the collection of boundary conditions as in equation (18) and $n$ is the outward unit normal along the fracture perimeter. Combine equation (25) with equation (14) leads to a nonlinear finite equation, which can be cast as

$$
F(w, \dot{w}, p)=0
$$

Take the temporal integration of above equation between $\left(t_{n}, t_{n+1}\right)$ at $t_{n+1}$ step leads to

$$
\int_{t_{n}}^{t_{n+1}} F(w, \dot{w}, p) d t=0
$$

Use the backward Euler scheme for time difference, then we get

$$
k\left(w_{n+1}\right) p_{n+1} \Delta t+G\left(w_{n+1}-w_{n}\right)+H \Delta t=0
$$

This equation can be generalized as

$$
M\left(\Delta w, \Delta p ; p_{n}, w_{n}\right)=0(29)
$$

Iterations are taken for these discretized equations. In equation (29), the unknowns are the latest fracture width $w_{n+1}$ and pressure $p_{n+1}$. Newton-Raphson algorithm is used as the iteration method 
to solve equations. Using equation (29), the fracture width and pressure at $n+1$ step can be obtained by known step $n$ value plus the increments $\Delta w$ and $\Delta p$ from equation (24).

The detailed iteration steps are as follows:

(i) Guess the initial value of $w_{n+1}$ and $p_{n+1}$, i.e. $w_{n+1}^{(0)}=w_{n}, p_{n+1}^{(0)}=p_{n}$. Define

$$
\begin{aligned}
& F_{1}\left(w_{n+1}, p_{n+1}\right)=w_{n+1}-E p_{n+1} \\
& F_{2}\left(w_{n+1}, p_{n+1}\right)=K\left(w_{n+1}\right) p_{n+1} \Delta t+G\left(w_{n+1}-w_{n}\right)+H \Delta t
\end{aligned}
$$

Where $E$ is the matrix in equation 24 , which can be calculated by model.

(ii) For $\mathrm{m}=0,1,2,3, \ldots \ldots$

(a) Calculate $R_{1}=F_{1}\left(w_{n+1}^{(m)}, p_{n+1}^{(m)}\right), R_{2}=F_{2}\left(w_{n+1}^{(m)}, p_{n+1}^{(m)}\right)$

(b) With the following equations

$$
\left[\begin{array}{cc}
\frac{\partial F_{1}}{\partial w_{n+1}} & \frac{\partial F_{1}}{\partial p_{n+1}} \\
\frac{\partial F_{2}}{\partial w_{n+1}} & \frac{\partial F_{2}}{\partial p_{n+1}}
\end{array}\right]\left\{\begin{array}{l}
\Delta w \\
\Delta p
\end{array}\right\}=\left\{\begin{array}{l}
R_{1} \\
R_{2}
\end{array}\right\}
$$

Solving $\Delta w$ and $\Delta p$ by

$$
\left\{\begin{array}{c}
\Delta w \\
\Delta p
\end{array}\right\}=\left[\begin{array}{cc}
\frac{\partial F_{1}}{\partial w_{n+1}} & \frac{\partial F_{1}}{\partial p_{n+1}} \\
\frac{\partial F_{2}}{\partial w_{n+1}} & \frac{\partial F_{2}}{\partial p_{n+1}}
\end{array}\right]^{-1}\left\{\begin{array}{l}
R_{1} \\
R_{2}
\end{array}\right\}
$$

(c) Update $w_{n+1}$ and $p_{n+1}$ by $w_{n+1}^{(m+1)}=w_{n+1}^{(m)}-\Delta w, p_{n+1}^{(m+1)}=p_{n+1}^{(m)}-\Delta p$

(iii) Repeat step (ii) until the specific tolerance $\varepsilon$ reached,

$$
\left\|w_{n+1}^{(m+1)}-w_{n+1}^{(m)}\right\| /\left\|w_{n+1}^{(m+1)}\right\| \leq \varepsilon
$$


After the simulation satisfies the tolerance, we can get the latest fracture width and pressure at time step $(n+1)$. Then repeat above steps to get fracture width and pressure for all time steps, which can be used for results characterization. 


\section{CHAPTER 3: Model Setup}

In this chapter, cases with different fracture number, fracture spacing and heterogeneities are constructed to investigate the influence of different parameters on fracture propagation and hydraulic fracturing optimization. First the single fracture case is built as the base case. Then models with two and three fractures are built. Fracture spacing varies from $5 \mathrm{~m}$ to $15 \mathrm{~m}$ for multiple fractures cases. Next, composite reservoir model with modified Poisson's ratio or Young's modulus will be constructed to resemble different level of heterogeneity in reservoir mechanical properties. Boundary and initial conditions are set for all models.

\subsection{Base case}

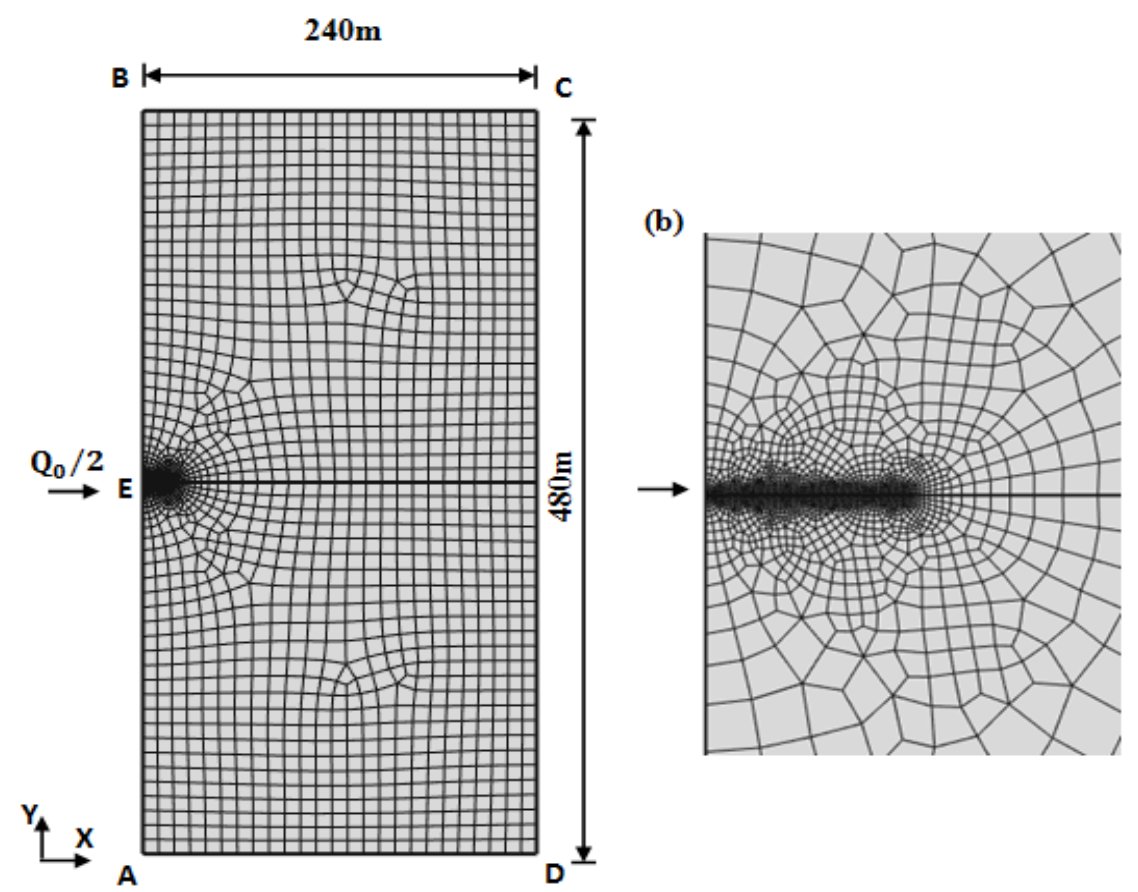

Figure 11. (a) Single fracture model with 100 elements on pre-defined fracture path (case 1). (b) Close view of fracture area.

The single fracture case is built as base case as shown in figure 11. Since we only consider half plane due to symmetry, the edge $\mathrm{AB}$ is fixed in $\mathrm{X}$ coordinate and point $\mathrm{C}$ and $\mathrm{D}$ are fixed in $\mathrm{Y}$ coordinate. The fluid is injected at point $\mathrm{E}$ with flow rate of half $\mathrm{Q}_{0}$. From point $\mathrm{E}$ to positive $\mathrm{X}$ coordinate, there is a $15 \mathrm{~m}$ pre-defined hydraulic fracture path. Since the overall dimension of this model is $240 \mathrm{~m} * 480 \mathrm{~m}$, it is large enough to represent the infinite solid medium surrounding the fracture. The initial fracture length starting form point $\mathrm{E}$ is set as $0.15 \mathrm{~m}$. The uniform initial 
pressure $p_{0}$ is applied in the fracture. This model is meshed with 3302 quad elements. An enlarged view of fracture area is shown in figure $11(\mathrm{~b})$. The view is set in a $30 \mathrm{~m} * 40 \mathrm{~m}$ box for better observation. Note the mesh around the pre-defined fracture path is much denser than other areas because our region of interest (ROI) is the fracturing area. There are 100 meshed elements on the pre-defined fracture path.

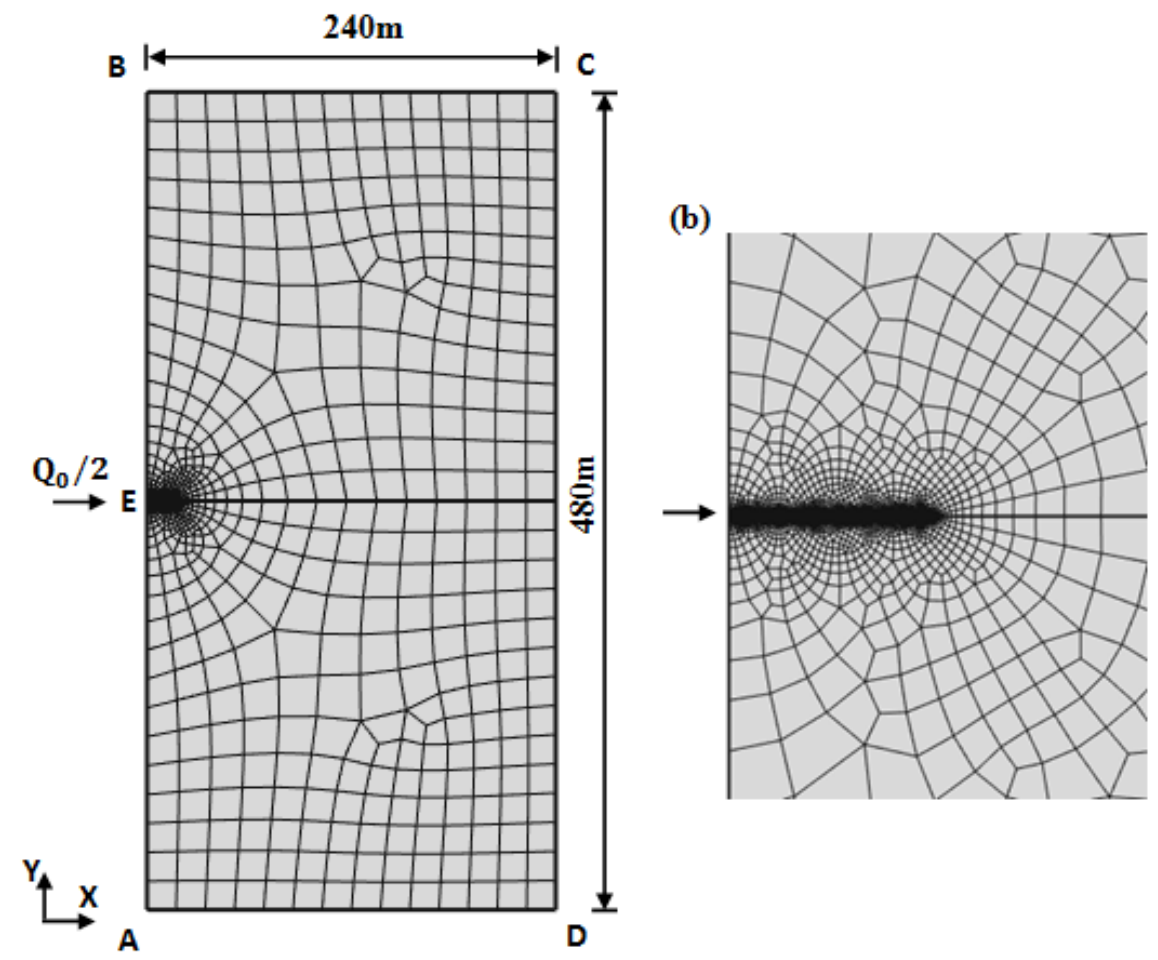

Figure 12. (a) Single fracture model with 200 elements on pre-defined fracture path (case 2). (b) Close view of fracture area.

To validate the simulation program, we construct the model with different mesh. Figure 12(a) shows the same model with 200 elements meshed on the pre-defined $15 \mathrm{~m}$ fracture path and coarser mesh in other areas. As we can see in figure 12(b), the mesh around the fracture is denser than it in figure 11(b). This model has 3894 quad elements in total.

For rock properties used in the simulation, the Young's modulus is 17Gpa and Poisson's ratio is 0.2 , which is common in Marcellus shale gas play. The fracture toughness is $1.458 \mathrm{Mpa} \cdot \sqrt{m}$. The leak-off coefficient for this medium is $1.47 \mathrm{e}-5 \mathrm{~m} / \sqrt{\mathrm{s}}$. For fluid properties, the dynamic viscosity of 
fluid is set as viscosity of water at $25^{\circ} \mathrm{C}$ and the flow rate is $0.001 \mathrm{~m}^{2} / \mathrm{s}$. In the simulation fluid flow rate at injection point is $0.0005 \mathrm{~m}^{2} / \mathrm{s}$ due to symmetry. The initial net fluid pressure applied in the fracture is $1 \mathrm{Mpa}$. The maximum horizontal stress is $500 \mathrm{Kpa}$ and minimum horizontal stress is $200 \mathrm{Kpa}$. The fracture propagates perpendicular to the minimum horizontal stress. Table 1 shows the summary of parameters used in the simulations.

Table 1. Parameters used in simulation

\begin{tabular}{|c|c|c|}
\hline Parameters & Denotation & Value \\
\hline Elastic modulus & $E$ & $17 \mathrm{GPa}$ \\
\hline Poisson's ratio & $v$ & 0.2 \\
\hline Injection flow rate & $Q_{0}$ & $0.001 \mathrm{~m}^{2} / \mathrm{s}$ \\
\hline Initial net fluid pressure & $p_{0}$ & $1 \mathrm{Mpa}$ \\
\hline Dynamic viscosity & $\mu$ & $9 \mathrm{e}-7 \mathrm{Kpa} / \mathrm{s}$ \\
\hline Leak-off coefficient & $C_{l}$ & $1.47 \mathrm{e}-5 \mathrm{~m} \sqrt{\mathrm{s}}$ \\
\hline Fracture toughness & $K_{I C}$ & $1.458 \mathrm{Mpa} \cdot \sqrt{m}$ \\
\hline
\end{tabular}

\subsection{Cases with different fracture number}

In order to test the influence of fracture number on the fracture propagation, cases with different fracture numbers are considered. Following the base case, models with two and three fractures are created. Having two and three fractures cases one can predict the behavior of as many fracture as fracture required in the model since both behavior of edge and center fractures can be modeled. Therefore the outcomes of these simulations can be applied to hydraulic fracturing process with arbitrary number of fractures.

The dimension of model is the same $240 \mathrm{~m} * 480 \mathrm{~m}$. Also, the mesh on the pre-defined fracture path is denser than other areas and the fracture spacing between fractures is kept at $5 \mathrm{~m}$. The fluid injection rate for each fracture is half of $Q_{0}$. For clarity in representation of fracture domain 
enlarged view of fracture area is shown in figure 13. The fracture area of three fractures case (case 4) is shown in figure 13(c) for comparison. The rock and fluid properties used in the simulation are the same as presented in the table 1.

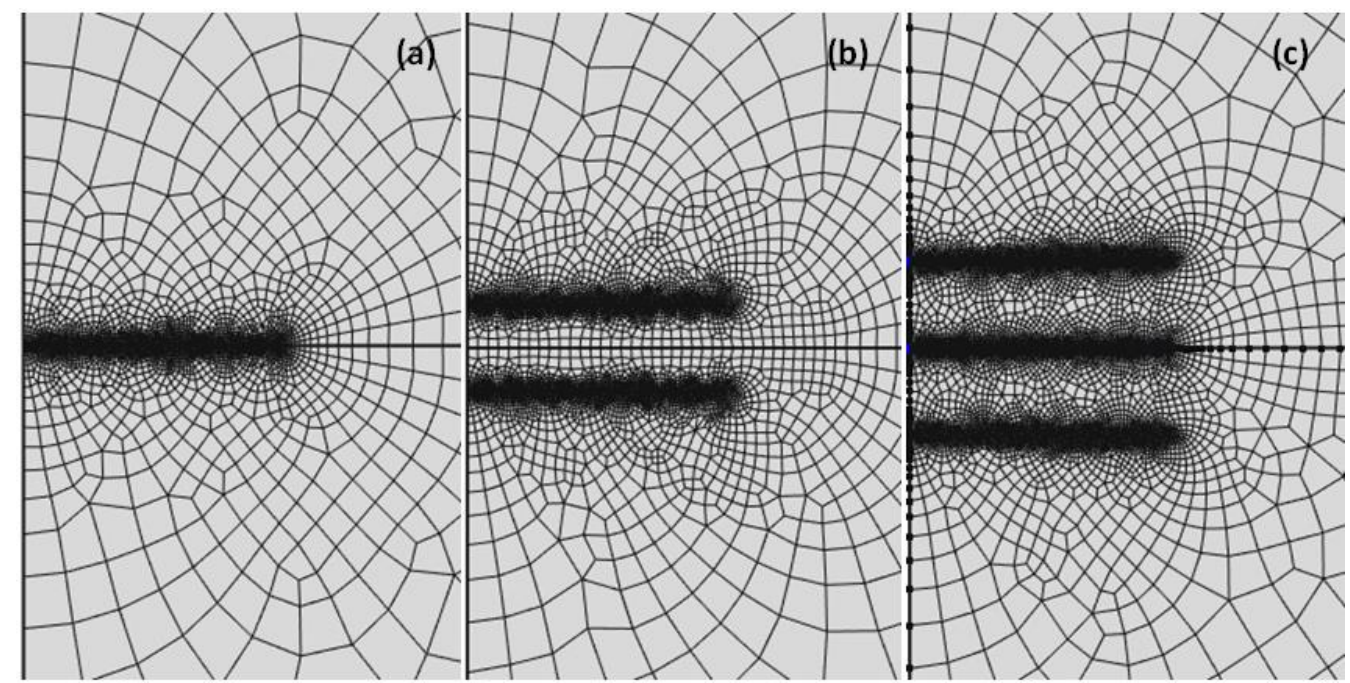

Figure 13. Close view of fracture area. (a) Single fracture model (case 1). (b) Two fractures model with $5 \mathrm{~m}$ spacing (case 3). (c) Three fractures model with $5 \mathrm{~m}$ spacing (case 4).

\subsection{Cases with different fracture spacing}

Fracture spacing can also impact fracture geometries and propagation rates. In majority of shale gas plays the cluster spacing is $50 \mathrm{ft}-100 \mathrm{ft}$. In this study, we consider fracturing spacing starts from $5 \mathrm{~m}$ to $15 \mathrm{~m}$ to see the effect of fracture spacing on fracture propagation as in this range mechanical interaction between fractures is stronger for characterization. Following similar procedure as discussed earlier with different fracture numbers will be used to discuss three fractures models with $5 \mathrm{~m}, 10 \mathrm{~m}$ and $15 \mathrm{~m}$ spacing.

Figure 14 show comparison of fracture area of three fracture cases with $5 \mathrm{~m}, 10 \mathrm{~m}$ and $15 \mathrm{~m}$ spacing. The rock and fluid parameters used in these models are also presented in the table 1 . The number of elements of these cases is about 10,000, which takes longer simulation time compared to single fracture case. 


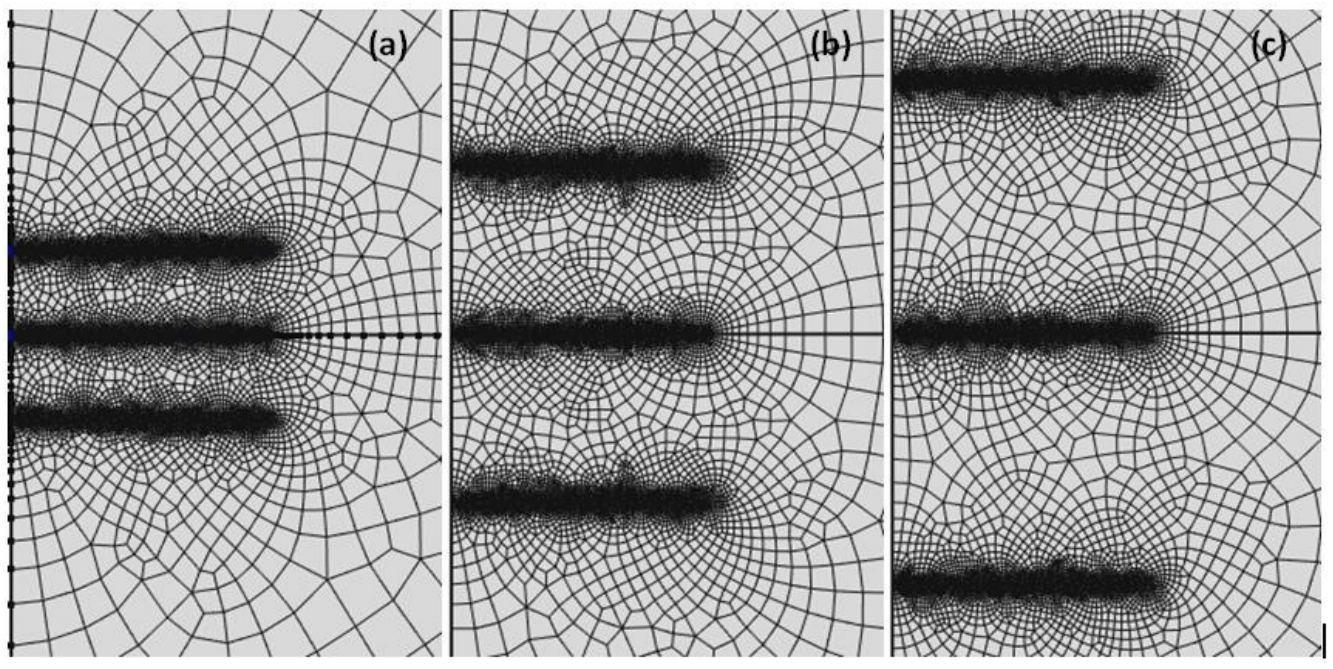

Figure 14. Close view of fracture area in (a) Three fractures model with $5 \mathrm{~m}$ spacing (case 4). (b) Three fractures model with $10 \mathrm{~m}$ spacing (case 5). (c) Three fractures model with $15 \mathrm{~m}$ spacing (case 6).

\subsection{Cases with different materials}

Figure 15 shows the illustration of composite model for our simulation, in which we consider the horizontal intersection as shown. Note that the boundary is not horizontal. Many rock parameters are accounted for affecting fracture propagation, such as Biot's constant, Young's modulus, Poisson's ratio, and horizontal stress ratio (Morrill and Miskimins, 2012). The model we built has different Poisson's ratio and Young's modulus in each material. In the first material, the Young's modulus and Poisson's ratio are 17Gpa and 0.2, respectively. For material 2, either the Young's modulus is modified to 10Gpa or Poisson's ratio is modified to 0.3.

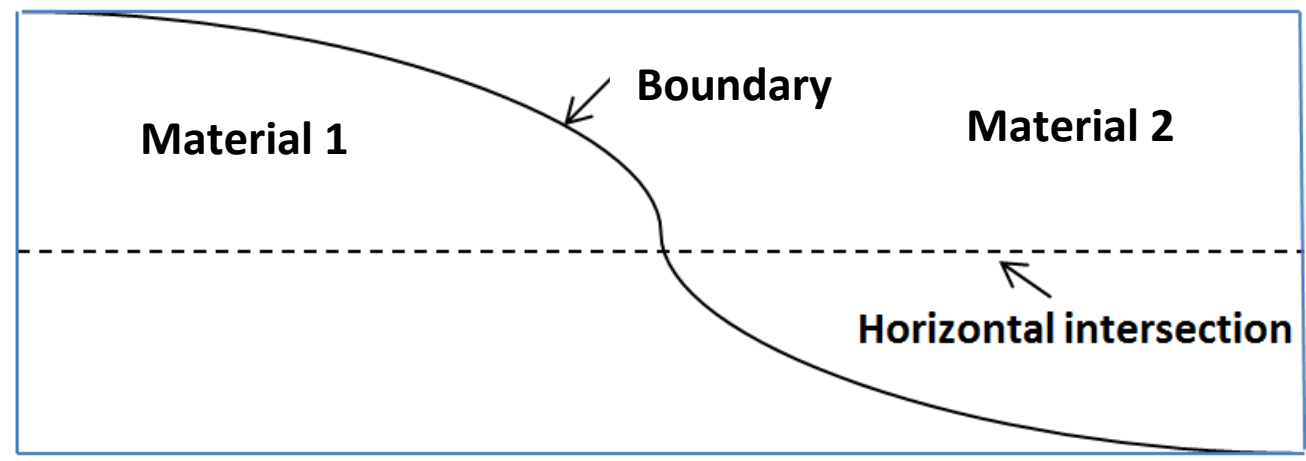

Figure 15. Illustration of composite reservoir model 

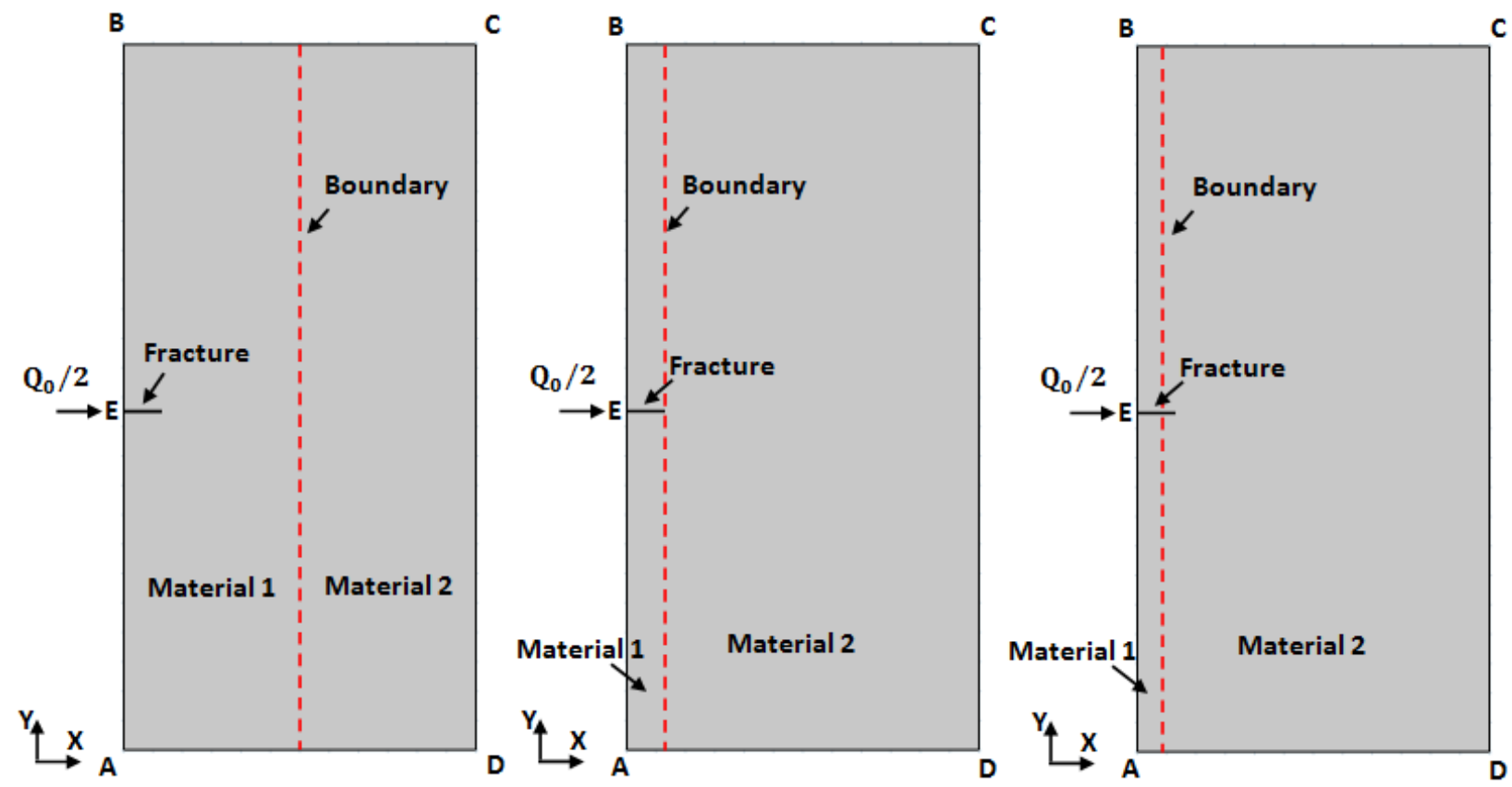

Figure 16. (a) Case 7 model with two materials. The boundary is far away from fracture. (b) Case 8 model with two materials. The boundary is close to the fracture. (c) Case 9 model with two materials. The boundary is across the fracture.

Another factor should be considered is the location of boundary. Case 7 has the boundary in the center of model, which represents the situation that the boundary is far away from the fracturing area. The boundary of case 8 lies close to the end of the fracture, which lies at $X=15 \mathrm{~m}$. Case 9 has the boundary at $X=10 \mathrm{~m}$, which means the fracture will cross the boundary. All other properties used in the simulation are same except the boundary. The schematic of these cases is shown in figure 16. For each case, the material 2 has either modified Young's modulus or modified Poisson's ratio.

Table 2 shows the summary of models we constructed in this chapter. Note that the difference between case 1 and case 2 is the mesh size. 
Table 2. Summary of cases

\begin{tabular}{|c|c|c|c|c|}
\hline Case ID & Fracture No. & Fracture spacing & Material No. & Boundary location \\
\hline 1 & 1 & N/A & 1 & N/A \\
\hline 2 & 1 & N/A & 1 & N/A \\
\hline 3 & 2 & $5 \mathrm{~m}$ & 1 & N/A \\
\hline 4 & 3 & $5 \mathrm{~m}$ & 1 & N/A \\
\hline 5 & 3 & $10 \mathrm{~m}$ & 1 & N/A \\
\hline 6 & 3 & $15 \mathrm{~m}$ & 1 & $\mathrm{X}=120 \mathrm{~m}$ \\
\hline 7 & 1 & $\mathrm{~N} / \mathrm{A}$ & 2 & $\mathrm{X}=15 \mathrm{~m}$ \\
\hline 8 & 1 & $\mathrm{~N} / \mathrm{A}$ & 2 & $\mathrm{X}=10 \mathrm{~m}$ \\
\hline 9 & 1 & $\mathrm{~N} / \mathrm{A}$ & 2 & \\
\hline
\end{tabular}




\section{CHAPTER 4: Results}

All cases described in chapter 3 are successfully simulated using an in-house simulator HFWVU. In this chapter, first we show results of single fracture cases. Results of case 1 and case 2 using different mesh sizes help us to make sure on robustness and mesh size independency of our program. Then results of other cases with different parameters (fracture number, fracture spacing, heterogeneity) are shown in each section, where the main focus is on the fracture geometries, propagation rates and stress profiles. The stress analysis helps us visualize the mechanical interaction between fractures and better understand the physics controlling the fracture geometry and propagation rate. Finally, slip tendency analysis of dynamic hydraulic fracturing indicates the possible fault reactivation zones.

\subsection{Single fracture cases}

Figure 17 shows fracture half-length and propagation rate for cases 1 and 2, i.e. different mesh size. The red dots represent case 1 with 100 elements on the pre-defined fracture path and blue dots represent case 2 with 200 elements on the pre-defined fracture path. The purple dots represent the analytic solution of half fracture-length derived from Bunger's paper for KGD model (Bunger, 2005). The good match with analytic solution indicates the robustness of program for simulating single fracture case.

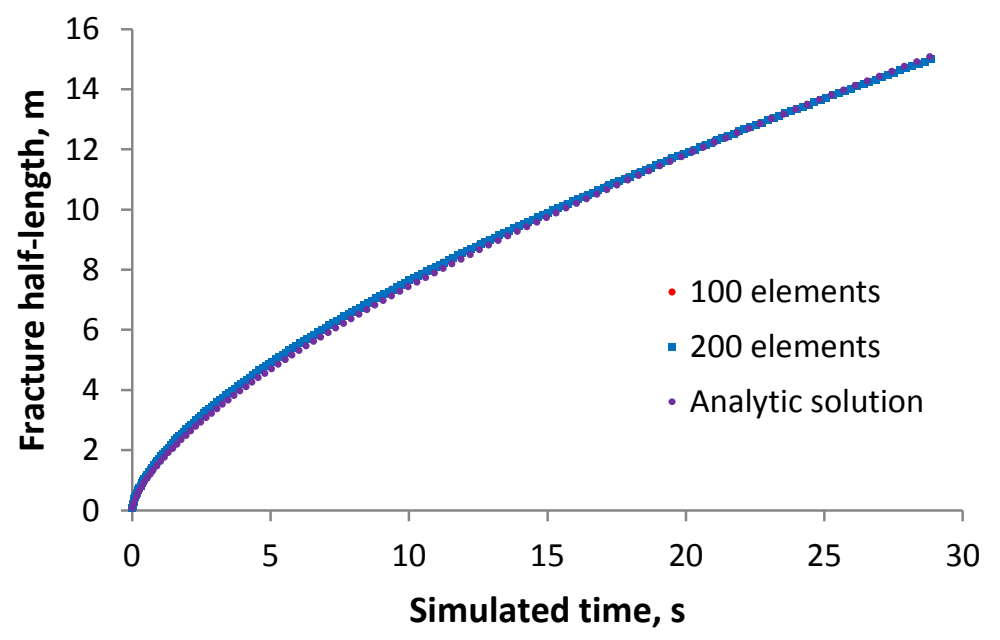

Figure 17. Fracture half-length of case 1 and case 2 with analytic solution 
The excellent match has also been obtained for these two cases indicating that even though the fracture propagation length is equal to element size at fracture tip however fracture half-length and propagation speed is mesh size independent. In order to reduce the simulation burden, the cases of multiple fractures simulated have coarser mesh in the model (100 elements on the predefined path). Note that the slope of real-time fracture half-length in figure 17 represents the propagation rate at that moment. Therefore, the fracture propagation rate at early time $(\mathrm{t}<5 \mathrm{~s})$ is nonlinear and higher than later time, this can be explained by higher energy dissipation due to fluid flow in longer fracture half-length as time passes. After five seconds of simulation, the fracture propagation rate tends to be constant.

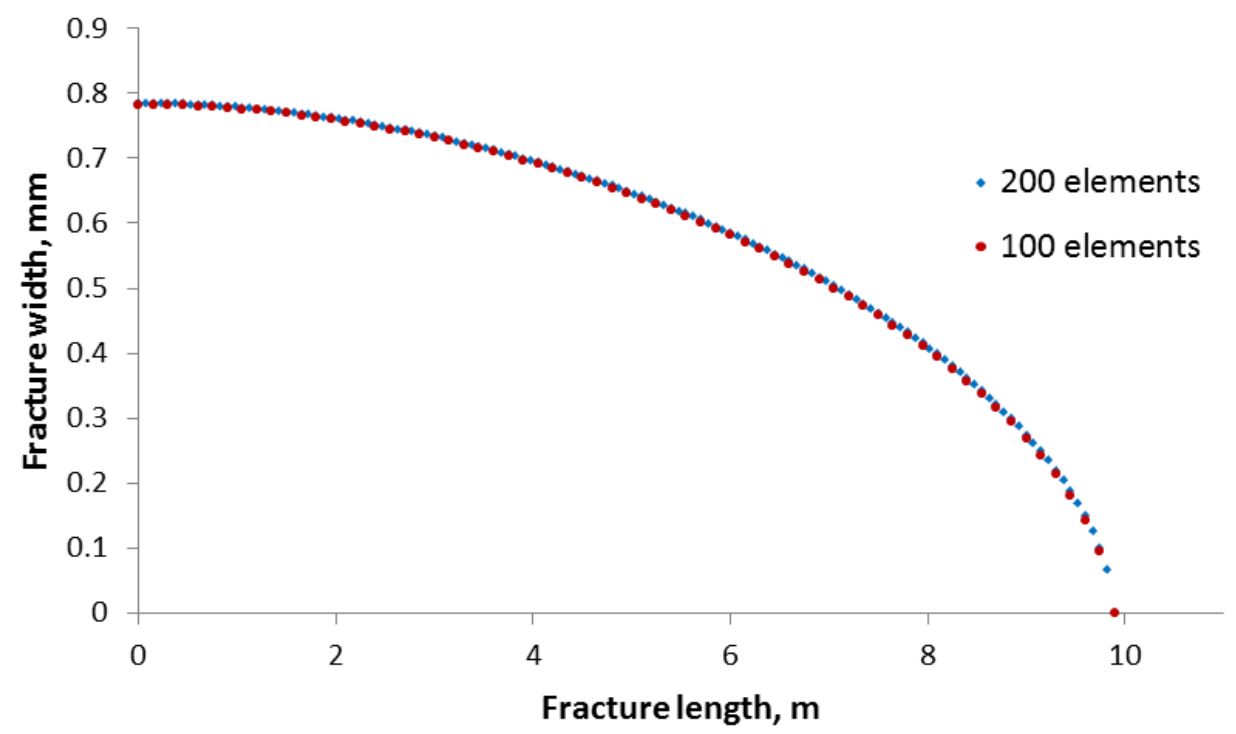

Figure 18. Fracture width of case 1 and case 2 at $t=15 \mathrm{~s}$

Figure 18 shows fracture width of these two cases across the fracture length at time step of 15 seconds. The fracture profile of case 1 and case 2 coincides with each other indicating the mesh size independency of simulations. The fracture tip is at $\mathrm{X}=9.9 \mathrm{~m}$, where the width equals to zero at this point.

Figure 19 shows the visualized fracture profile of half model of case 1 at $t=15 \mathrm{~s}$. The magenta part represents fluid/fracture and the blue part represents surrounding solid medium. The fracture width has been magnified by 2000 times and the view is set in a $10 \mathrm{~m} * 2 \mathrm{~m}$ block for illustration purposes. The elliptic shape of fracture profile has good agreement with KGD model assumption. 


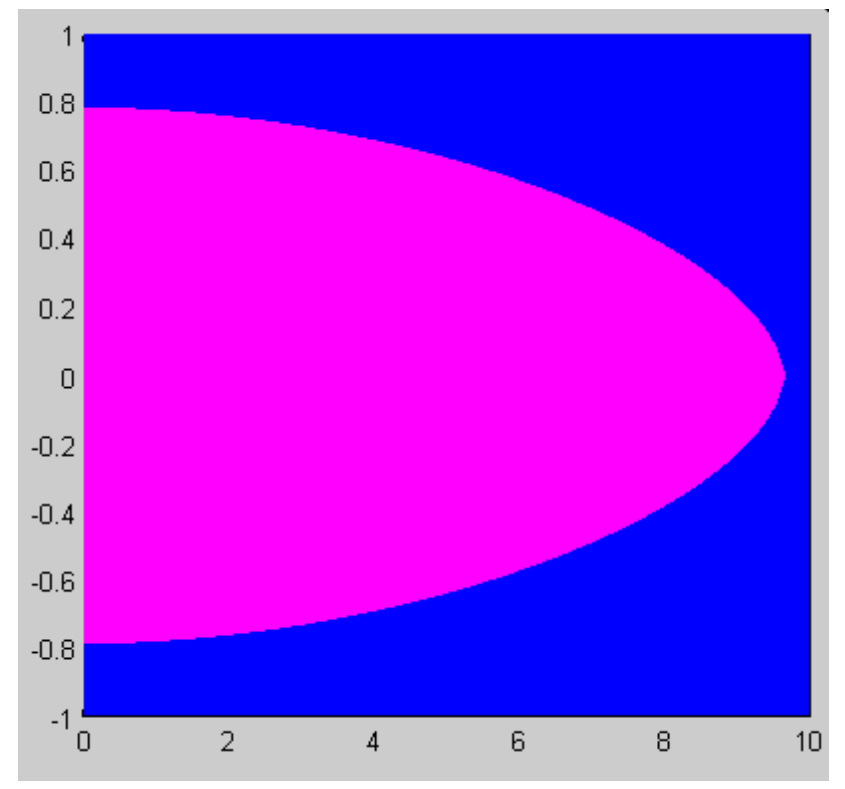

Figure 19. Fracture profile of case 1 at $t=15 \mathrm{~s}$

Figure 20 shows the pressure profile of case 1 and case 2 at $t=15 \mathrm{~s}$. The pressure decrease around the fracture tip is quite steep and a negative singularity occurs at the fracture tip. This can be explained by the logarithmic singularity of pressure analytical solution as following (Hu, 2009)

$$
p=\frac{\mu^{\prime} E^{\prime 2}}{K^{\prime 2}}\left[\frac{d \ell}{d t}+\frac{C^{\prime} \mu^{\prime} E^{\prime}}{K^{\prime}}\left(\frac{d \ell}{d t}\right)^{\frac{1}{2}}\right] \ln \frac{(\ell-x)}{\ell}
$$

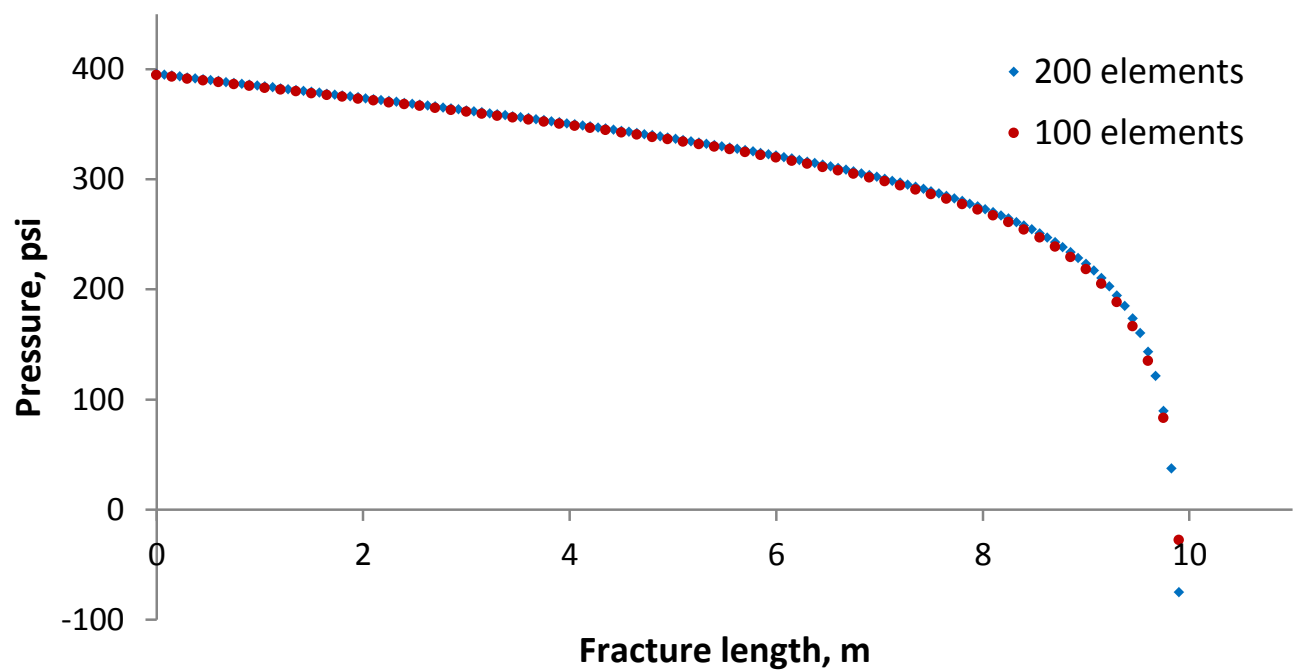

Figure 20. Pressure profile of case 1 and case 2 at $t=15 \mathrm{~s}$ 
Figure 21 shows the change of minimum horizontal stress of case 1 at $t=15 \mathrm{~s}$. The fracture width has been enlarged 2000 times and the view is set in a $30 \mathrm{~m} * 30 \mathrm{~m}$ block. The magenta part in this figure represents the fluid part. The magnitude of stress change can be referred to the color bar on the right side. Note that the negative sign in this figure represents increase of compressive stress.

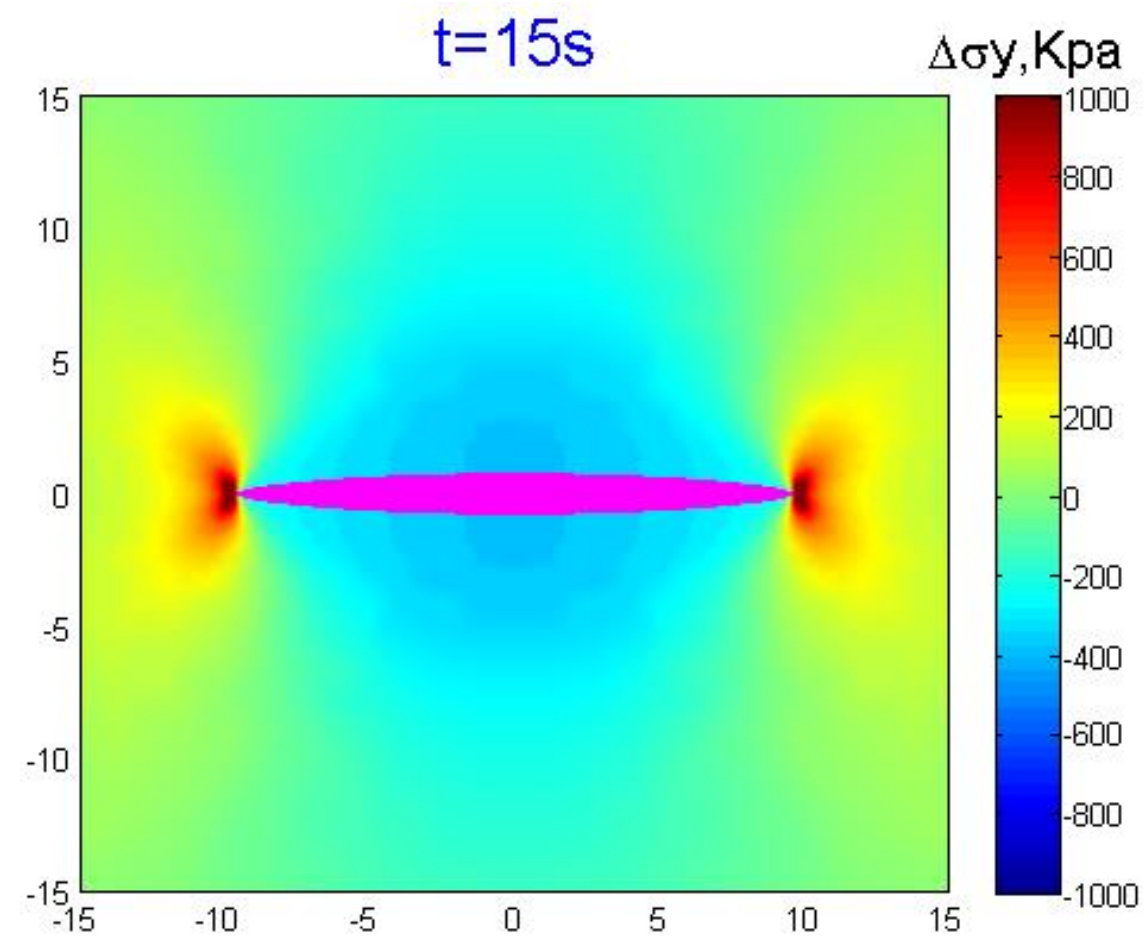

Figure 21. Change of minimum horizontal stress of case 1 at $t=15 \mathrm{~s}$

The stress change around the fracture is negative from 0 to $-200 \mathrm{kPa}$. This indicates stress alteration induced by hydraulic fracturing. While in front of fracture tips, the stress change is positive. This is due to the fact that fracture propagation causes the tensile stress and it is against the compressive stress around the fracture tips, which results the increase of minimum horizontal stress near the fracture tips. 


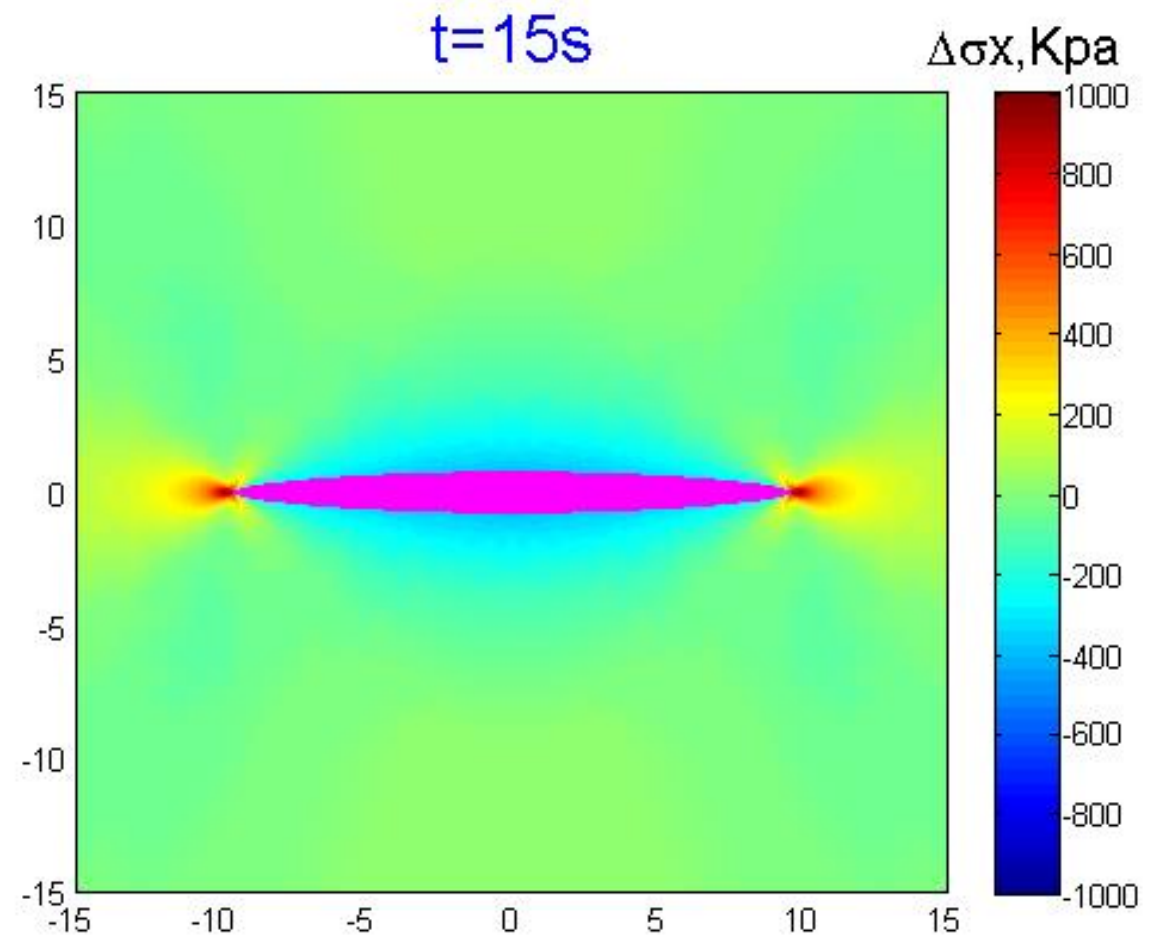

Figure 22. Change of maximum horizontal stress of case 1 at $t=15 \mathrm{~s}$

Figure 22 shows the change of maximum horizontal stress for case 1 at $t=15 \mathrm{~s}$. It is interesting that the similar pattern as seen in minimum horizontal stress is observed for maximum horizontal stress. The stress change is also negative perpendicular to fracture and positive in front of fracture tips. The stress change around the fracture decreases from the fracture center to the tip. The maximum horizontal stress has change up to $1000 \mathrm{kPa}$ around the tips. 


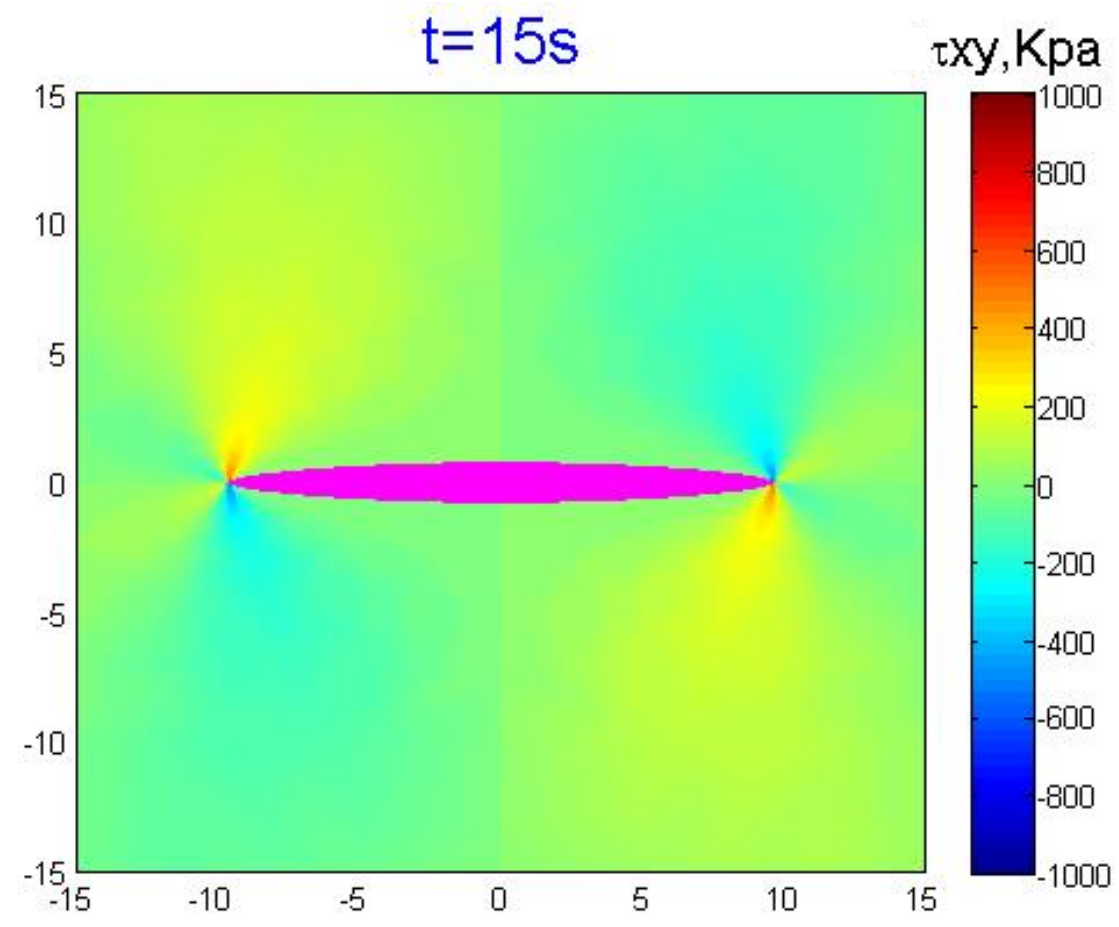

Figure 23. Shear stress of case 1 at $\mathrm{t}=15 \mathrm{~s}$

Figure 23 shows the shear stress profile of case 1 at $t=15 \mathrm{~s}$. The purpose of analyzing shear stress is to target possible fault reactivation zones during hydraulic fracturing, which will be discussed in section 4.6. The positive or negative sign of shear stress in this figure represents direction only. As observed, the shear stress around fractures tips increases significantly, which indicates the possibility of slippage in these areas. The increase of shear stress may reactivate pre-existing fractures or faults in the surrounding area.

\subsection{Two fractures case}

Figure 24 shows fracture profile of two fractures generated and propagated simultaneously at $\mathrm{t}=15 \mathrm{~s}$. Unlike single fracture case, each fracture is no longer axisymmetric. The inner fracture side has flattened out due to mechanical interactions (compression). The fracture half-length increases to $11 \mathrm{~m}$ compared to $9.5 \mathrm{~m}$ of single fracture case in figure 19 while rest of parameters are the same except number of fractures simultaneously generated. The fracture width decreases to some extent, which will be discussed with three fractures case later. 


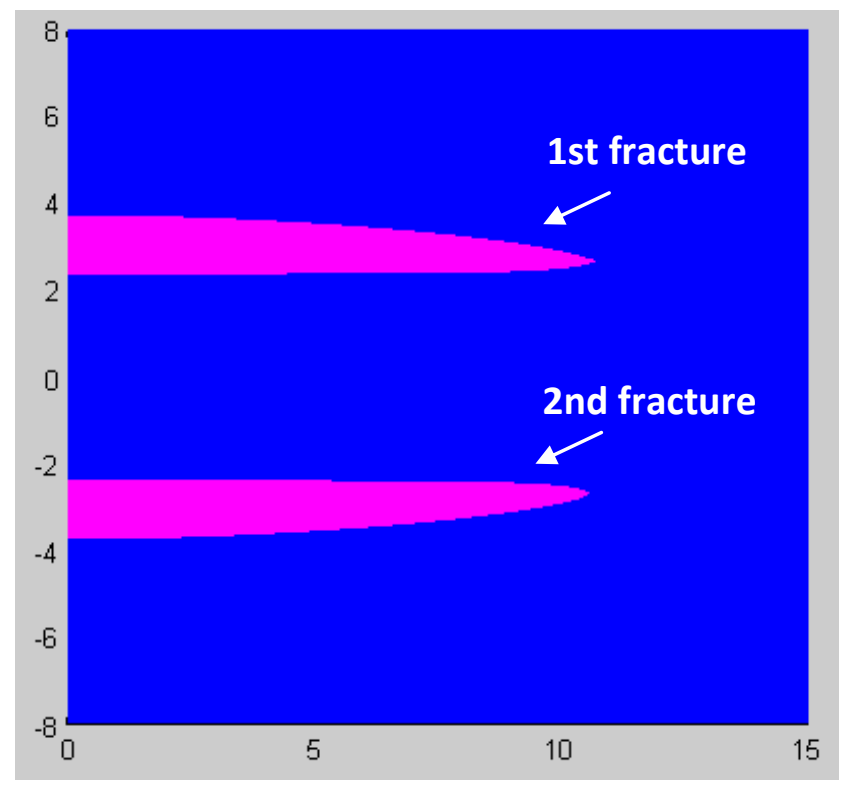

Figure 24. Fracture profile of case 3 at $t=15 \mathrm{~s}$

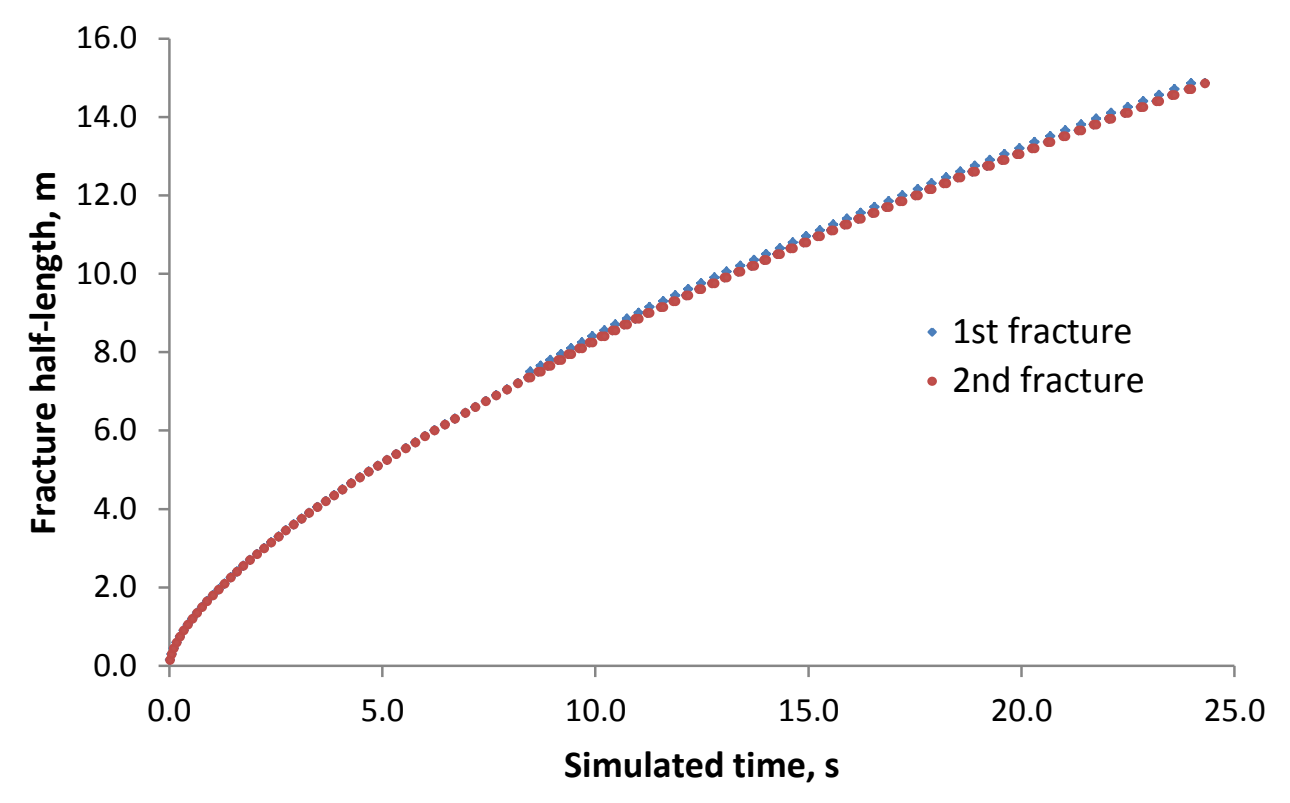

Figure 25. Fracture half-length of case 3 at $t=15 \mathrm{~s}$ 


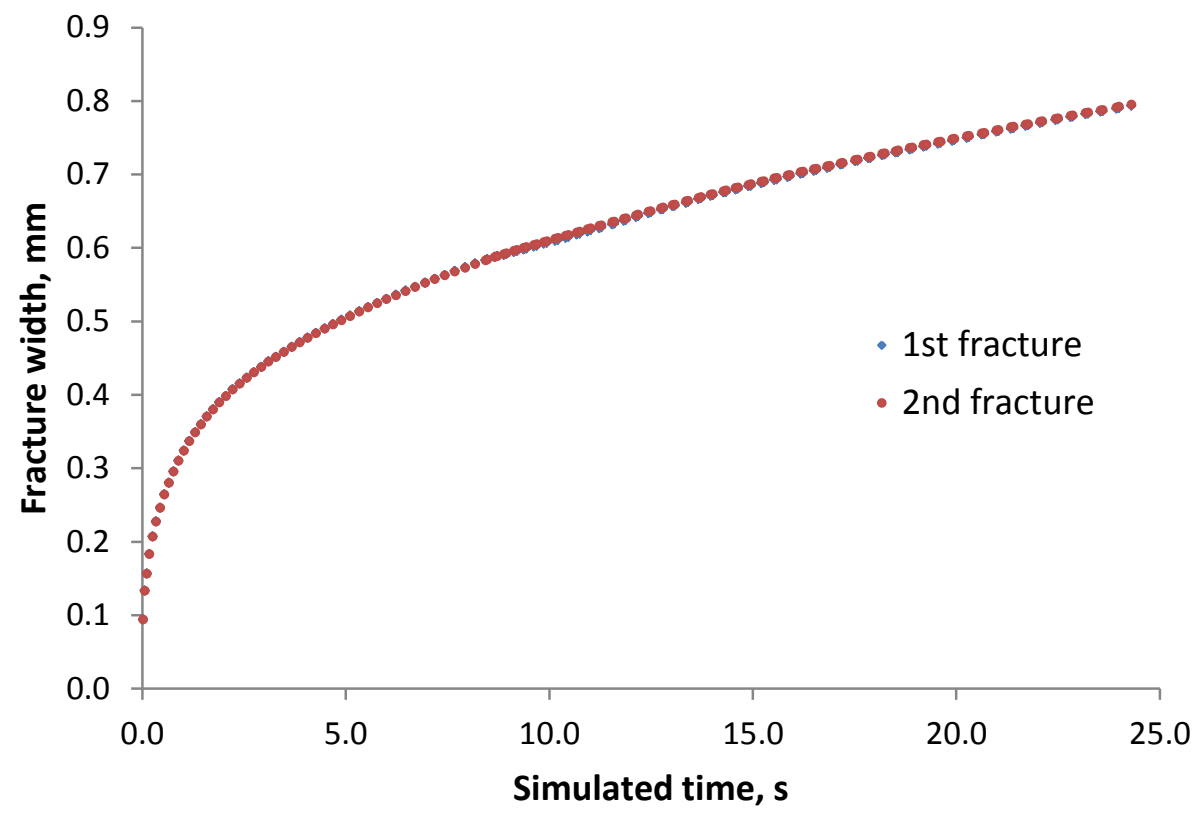

Figure 26. Fracture width at injection point of case 3 at $t=15 \mathrm{~s}$

Figure 25 and 26 shows fracture half-length and fracture width at injection point for case 3 at $t=15 s$, respectively. Blue dots represent first fracture $(y>0)$ and red dots represent second fracture $(y<0)$ in figure 24. We can conclude that good match of profiles for both fractures validate the robustness of program for simulating multiple fractures. Due to symmetry and homogeneous rock and fluid properties both fractures show same half-length, propagation rate and width dynamics with time.

\subsection{Effect of number of fractures}

In this section, we discuss the effect of fracture number on propagation by analyzing results of single, two and three fractures cases. The fracture profile of case 1 , case 3 and case 4 at $t=10 \mathrm{~s}$ presented in figure 27 for comparison. Fracture width in Y direction is magnified by 2000 times and the view is set in a $9 \mathrm{~m}^{*} 16 \mathrm{~m}$ box for illustration purposes. 

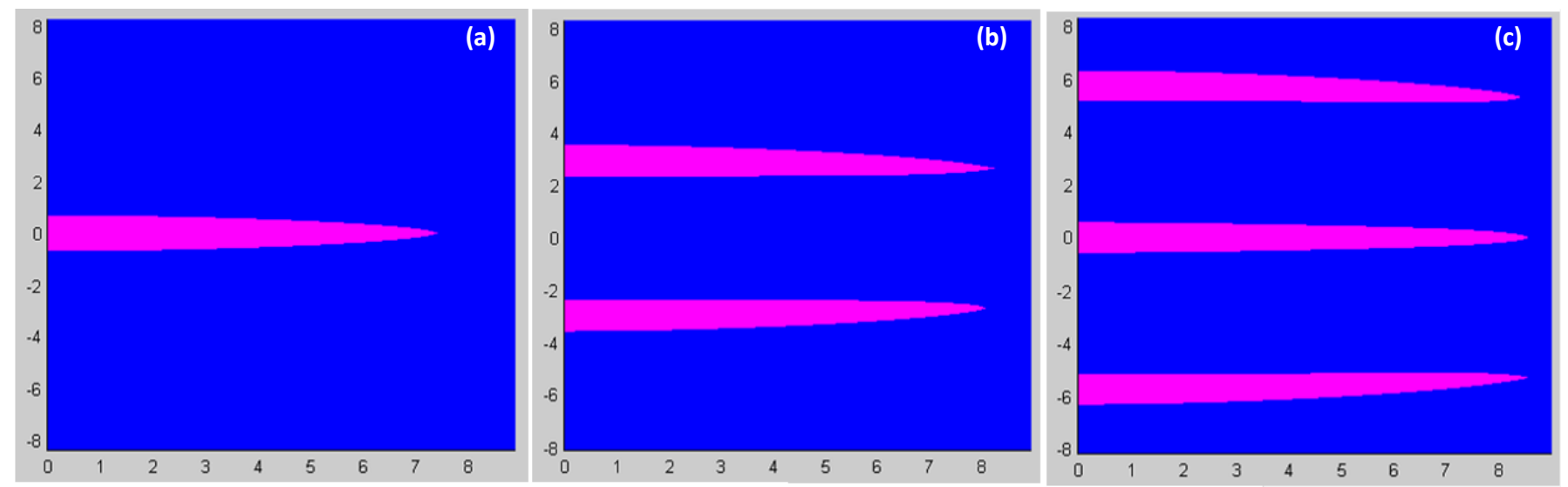

Figure 27. Fracture profile of case 1 , case 3 and case 4 at $t=10 \mathrm{~s}$

For three fractures case, the geometry of center fracture is similar to single fracture case, which is axisymmetric, and side fractures are similar to two fractures case, which are non-axisymmetric. The simulation results show that the center fracture has smaller width and longer length compared to edge fractures in three fractures simultaneously generated in Figure 27(c). The same deviations happen to the edge fractures, which are due to mechanical interactions between center fracture and edge fractures. The half-length of these fractures increases from $7.5 \mathrm{~m}$ (case 1) to $8.5 \mathrm{~m}$ (case 4), which indicates as fracture number increases, the fracture length increases. For fracture width, it decreases to some extents, which will be quantified later. The stress compression between fractures makes each fracture to have smaller fracture width and longer fracture length.

Next, fracture half-length and width of fractures for each case is investigated. Figure 28 shows the fracture half-length of case 1 , case 3 and case 4 with time evolution. Note that we pick the center fracture as basis for comparison in three fractures case. Since the slope of the change in fracture length with time represents the fracture propagation rate, at early time all fractures propagate almost with same speed $(\mathrm{t}<2 \mathrm{~s})$, however as time passes 3 fractures case propagates faster than two and that faster than single fracture case. Therefore, as fracture number increases, the fracture propagates faster and has longer fracture half-length, which is more obvious at the later time $(t>5 s)$ of hydraulic fracturing as illustrated in figure 28. 


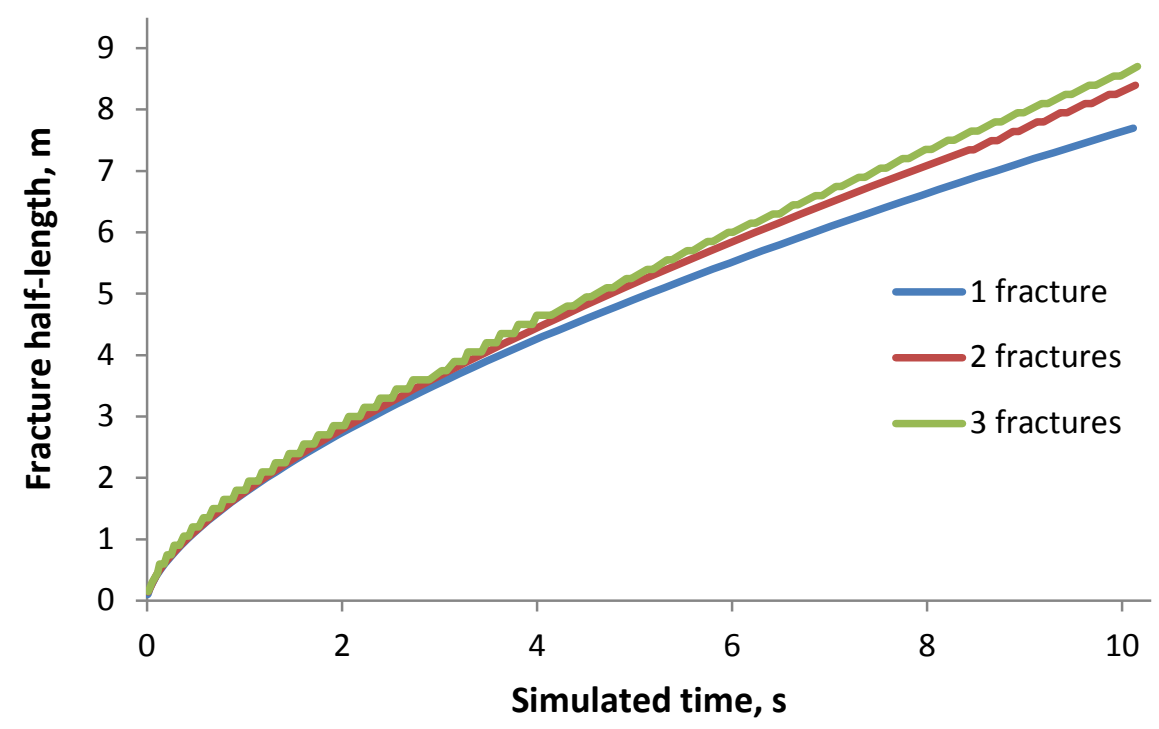

Figure 28. Fracture half-length of case 1, case 3 and case 4

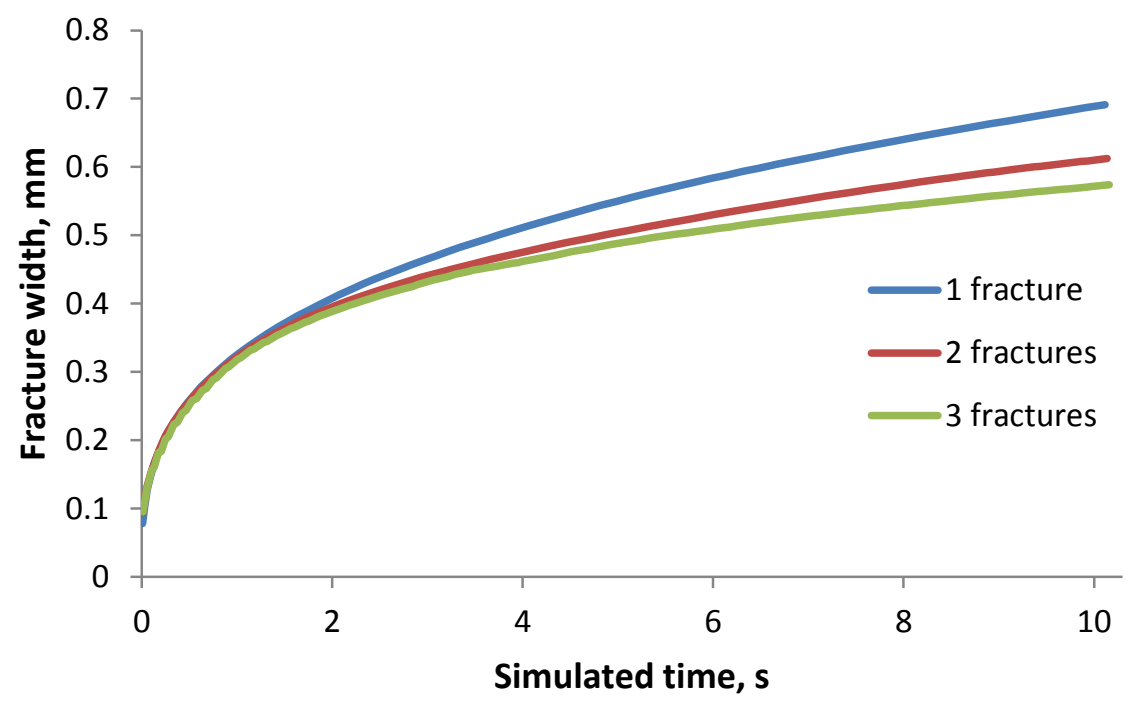

Figure 29. Fracture width at injection point of case 1, case 3 and case 4

Figure 29 compares the fracture width at injection point for different cases 1,3 and 4 . The fracture width increases rapidly at the early time and slows down at late times $(t>5 s)$, that shows positive correlation with fracture propagation rate. The results also show that as fracture number increases, the fracture width decreases. This is due to fact that stress concentration induced by hydraulic fracturing between fractures becomes stronger as fracture number increases. As figure 28 and figure 29 shows, the compression stresses between fractures can play the main role in 
increasing the fracture half-length and decreasing the fractures width. This effect is known as fracture shadow effect and studied well in the literature Cheng, 2009; Cheng, 2012. The compressive stress induced by more fractures becomes stronger which results faster propagation and smaller fracture width.

Advanced understanding of change in fracture geometry and propagation rate can be obtained having closer look at dynamics of change in minimum and maximum horizontal stresses and tensile stress. Figure 30 illustrate the change of minimum horizontal stress of case 1 and case 3 at same time step $\mathrm{t}=8 \mathrm{~s}$. The fracture width is magnified by 1000 times and the view is set in a $30 \mathrm{~m} * 30 \mathrm{~m}$ block. The magenta part in this figure represents the fluid/fracture.
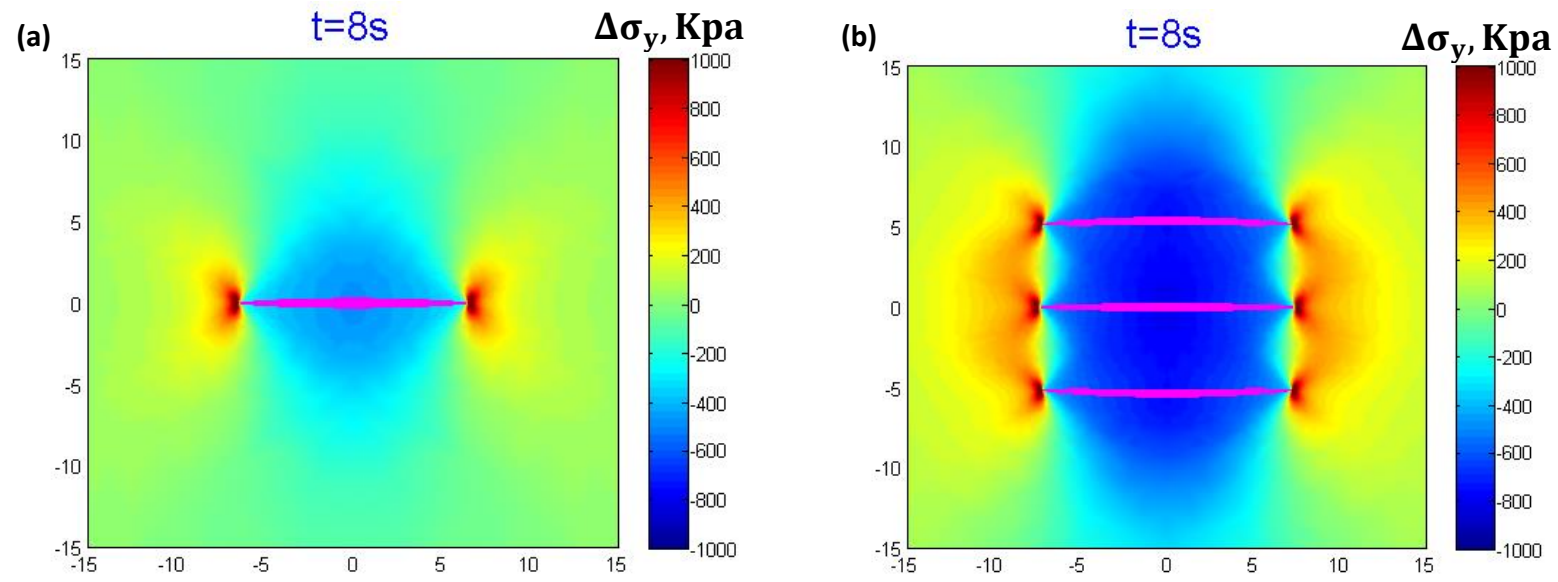

Figure 30. (a) Change of minimum horizontal stress of case 1 at $t=8 \mathrm{~s}$. (b) Change of minimum horizontal stress of case 4 at $\mathrm{t}=8 \mathrm{~s}$.

The magnitude of stress change can be referred to the color bar on the right side. For case 1, the stress change perpendicular to the fracture is about $300 \mathrm{Kpa}$, while in case 4 , the stress change between fractures is about $600 \mathrm{kPa}$. This increase of stress change indicates the stress concentration or stress shadow between fractures in case 4 . The stronger stress alteration between fractures results in longer fracture length and smaller fracture width as fracture number increases. 


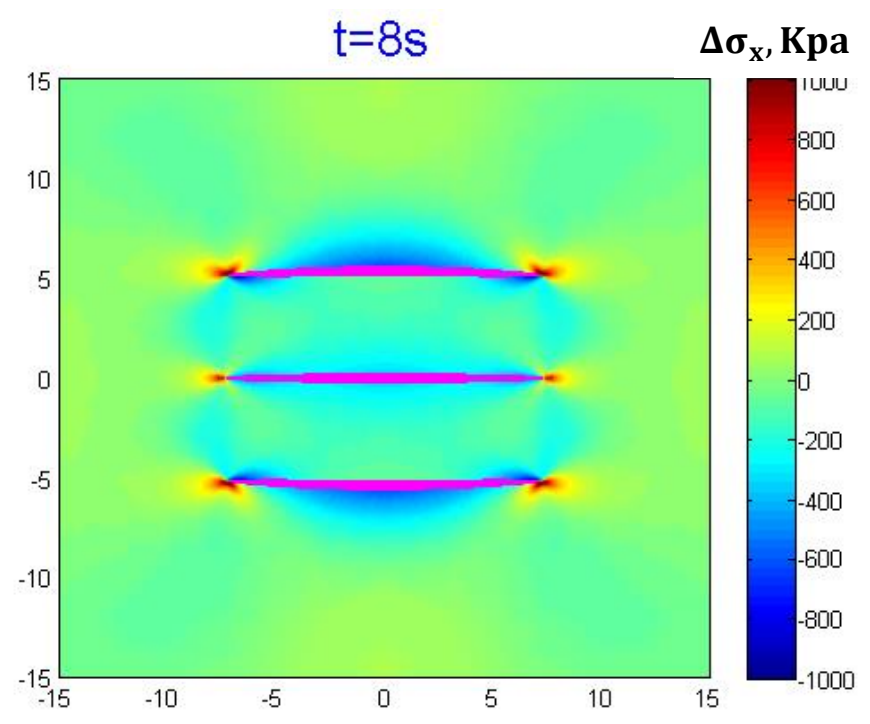

Figure 31. Change of maximum horizontal stress of case 4 at $t=8 \mathrm{~s}$

Figure 31 illustrates the change of maximum horizontal stress in case 4 at $t=8 \mathrm{~s}$. The change of maximum horizontal stress decreases between center fracture and edge fractures. Around the fracture tips, the maximum horizontal stress change is up to $1000 \mathrm{kpa}$.

\subsection{Effect of fracture spacing}

Next the effect of fracture spacing in geometry and propagation of simultaneously created multiple fractures is considered. Figure 32 shows the fracture profile of three cases (case4, case 5 and case 6$)$ at $\mathrm{t}=8 \mathrm{~s}$. Note that case 3 , case 4 and case 5 has fracture spacing of $5 \mathrm{~m}, 10 \mathrm{~m}$ and $15 \mathrm{~m}$, respectively as presented in Table 2 . The fracture width is magnified by 2000 times and the view is set in an $8 \mathrm{~m} * 30 \mathrm{~m}$ block for illustration purposes.

As fracture spacing increases, the fracture length becomes shorter $(7.2 \mathrm{~m}$ to $6.6 \mathrm{~m})$ and fracture width becomes wider. That is due to mechanical interaction between fractures discussed earlier. Hence with weaker mechanical interaction, each fracture propagates slower and suffers smaller stress compression with leading to larger fracture width. The mechanical interaction can also be quantified as shown in figure 30. 

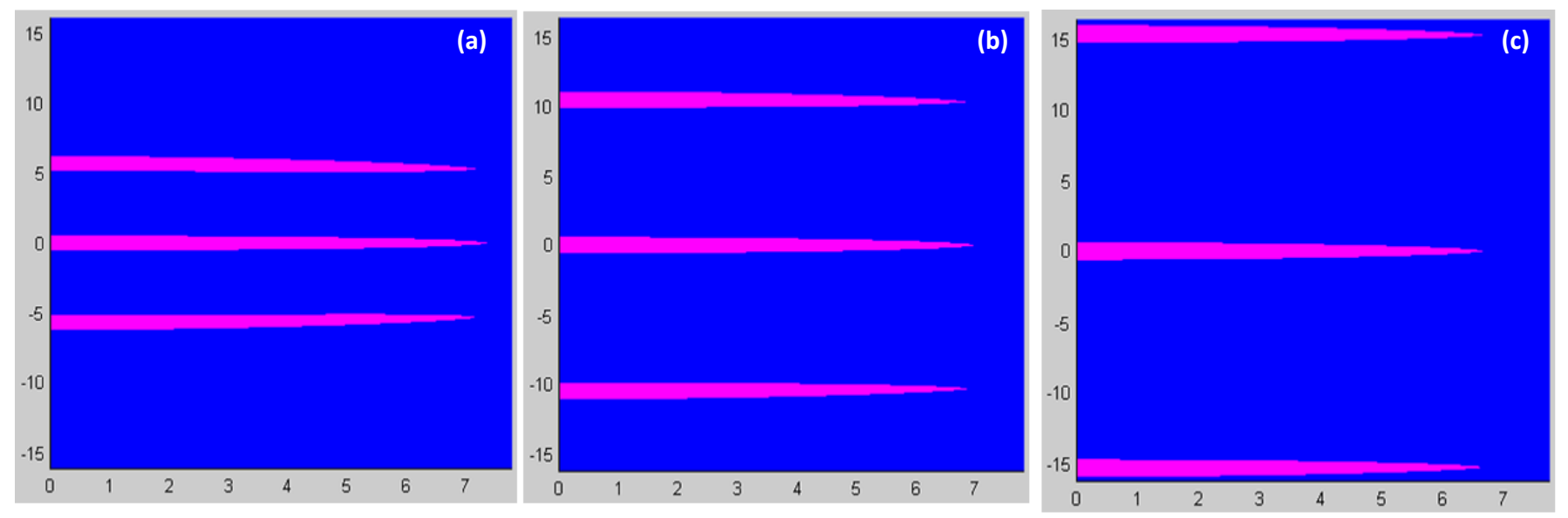

Figure 32. Fracture profile of case 4 , case 5 and case 6 at $t=8 \mathrm{~s}$

Figure 33 shows fracture half-length over time for these three different cases. We pick the center fracture as basis for comparison. As fracture spacing increases, the fracture half-length becomes shorter, which means the propagation is slower. So the fracture half-length has a negative relationship with fracture spacing.

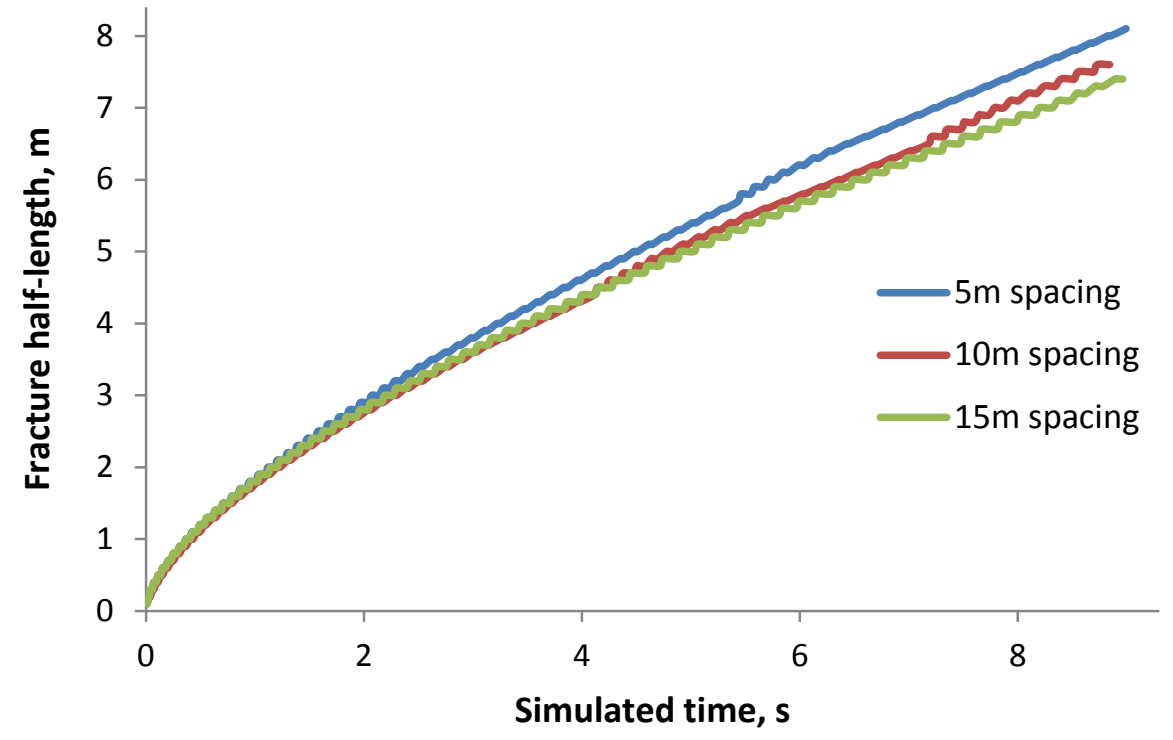

Figure 33. Fracture half-length of case 4, case 5 and case 6 


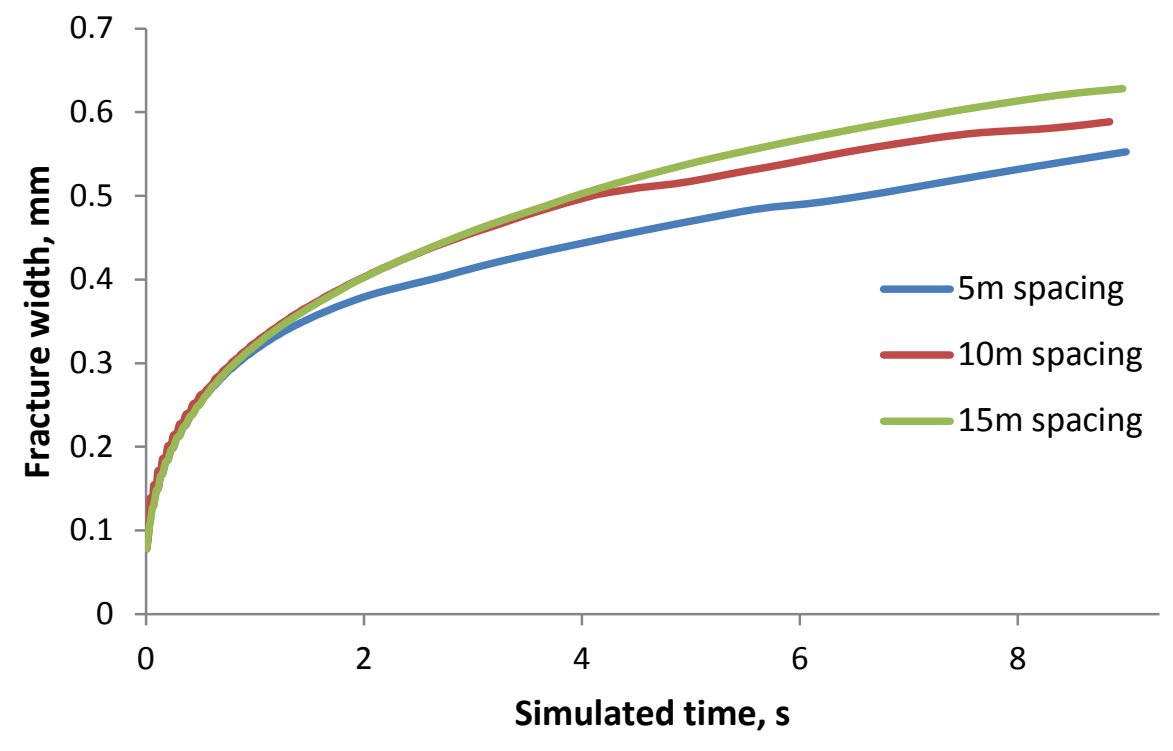

Figure 34. Center fracture width at injection point of case 4, case 5 and case 6

Figure 34 also shows center fracture width at injection point of three cases. In this case, the fracture width has positive relationship with fracture spacing. The larger spacing between fractures decreases mechanical interactions from side fractures on the center fracture which results in larger fracture width.

\subsection{Heterogeneous effect}

In this section, we discuss different cases with multiple materials (case 7, case 8 and case 9). In Figure 35 three different cases is considered where the heterogeneity in mechanical properties of the formation, i.e., two materials, assigned using different Poisson's ratio values ( 0.2 and 0.3 for material 1 and 2 respectively). Next the boundary between two materials is place far away from expected fracture tip, i.e., case 6 , close to fracture tip which is case 7 and where the fracture paces the boundary in case 8 . The fracture half-length for all cases is obtained during the simulation time and plotted in figure 35. Figure 35 clearly shows the change in Poisson's ratio from 0.2 to 0.3 in two materials does not impact fracture half-length no matter where the interface is located. 


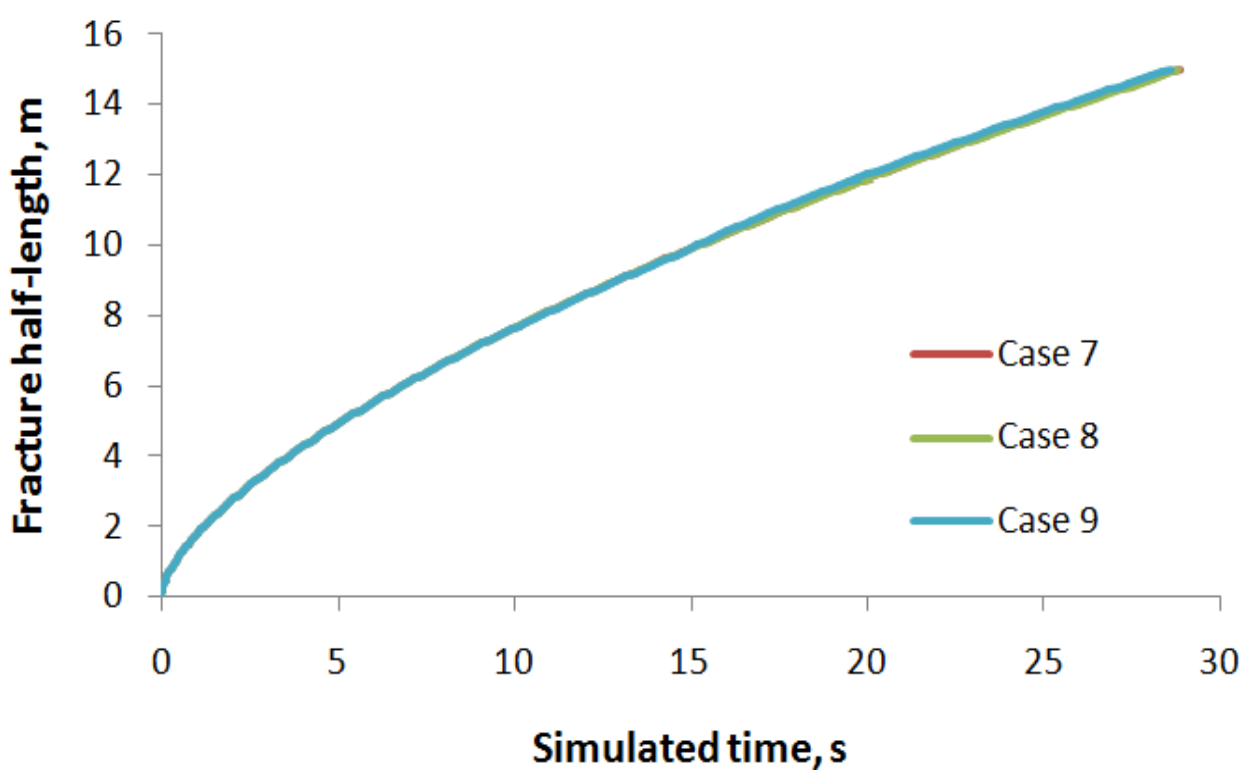

Figure 35. Fracture half-length of cases with modified Poisson's ratio

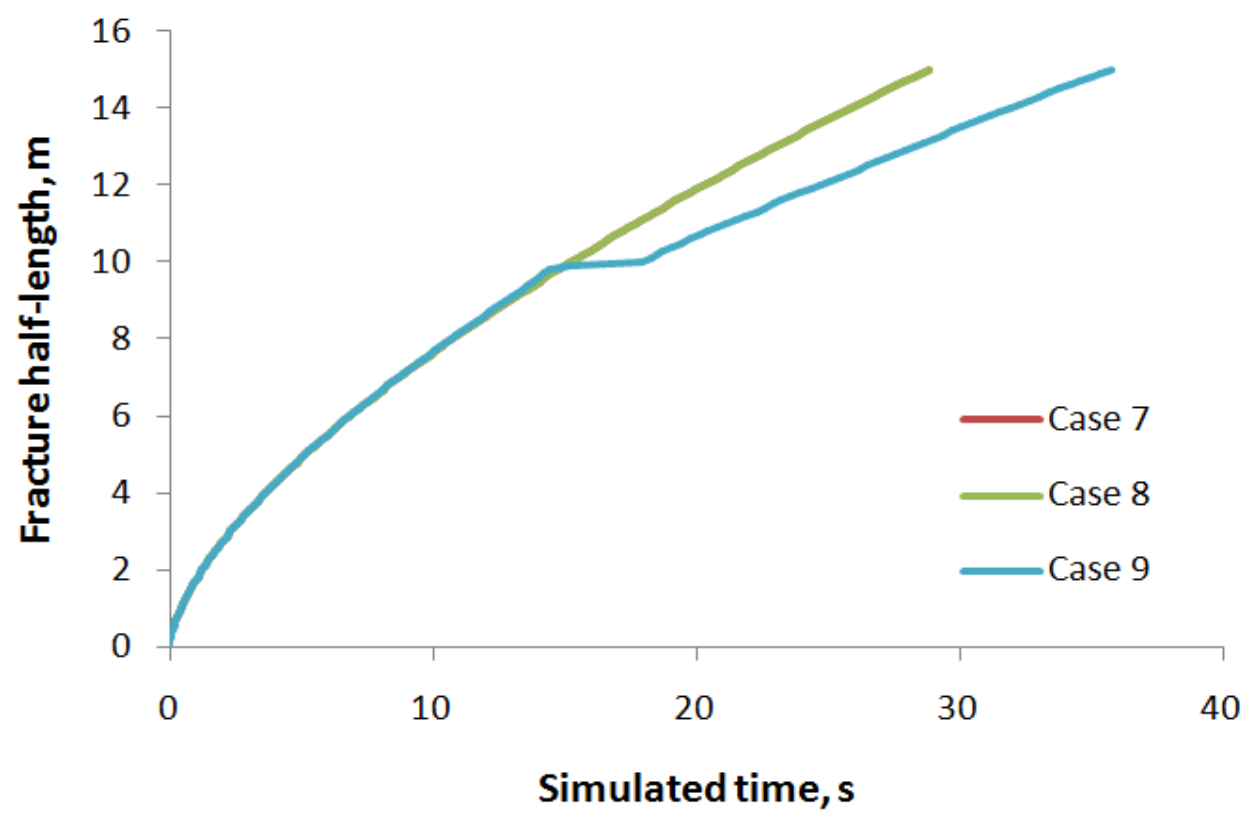

Figure 36. Fracture half-length of cases with modified Young's modulus

Figure 36, however, shows fracture half-length of cases where the heterogeneity of the formation in different materials is applied assuming different Young's modulus for each material. In this case the location of the interface between two materials clearly influences the fracture half-length and propagation rate. As long as fracture does not pass two materials boundary the difference between Young modulus in two materials does not impact the fracture propagation. However, it is 
clear in case 8 that as fracture enters the second material with smaller young modulus there is a distinct retardation in fracture propagation. Then after passing the boundary, the propagation rate (slop of curve) slows down compare to other cases. It is due the fact that the Young's modulus dropped from $17 \mathrm{Gpa}$ to $10 \mathrm{Gpa}$ in material 2.

\subsection{Fault reactivation analysis}

Here the potential seismicity risk associated with hydraulic fracturing and therefore any fault reactivation or discontinuity failure is investigated. Figure 37 shows an example of the shear stress change of case 3 , with three fracture simultaneously created, at $t=8 \mathrm{~s}$. It is well studied that the main requirement for a discontinuity or fault to slip on its plane is when shear stress $\tau$ exceeds the frictional sliding resistance. Figure 37 clearly shows the shear stress around fractures tips increases significantly, especially around edge fractures tips. The magnitude of shear stress change indicates the possibility of slippage in these areas, which may reactivate pre-existing fractures or faults if presented at critical stage.

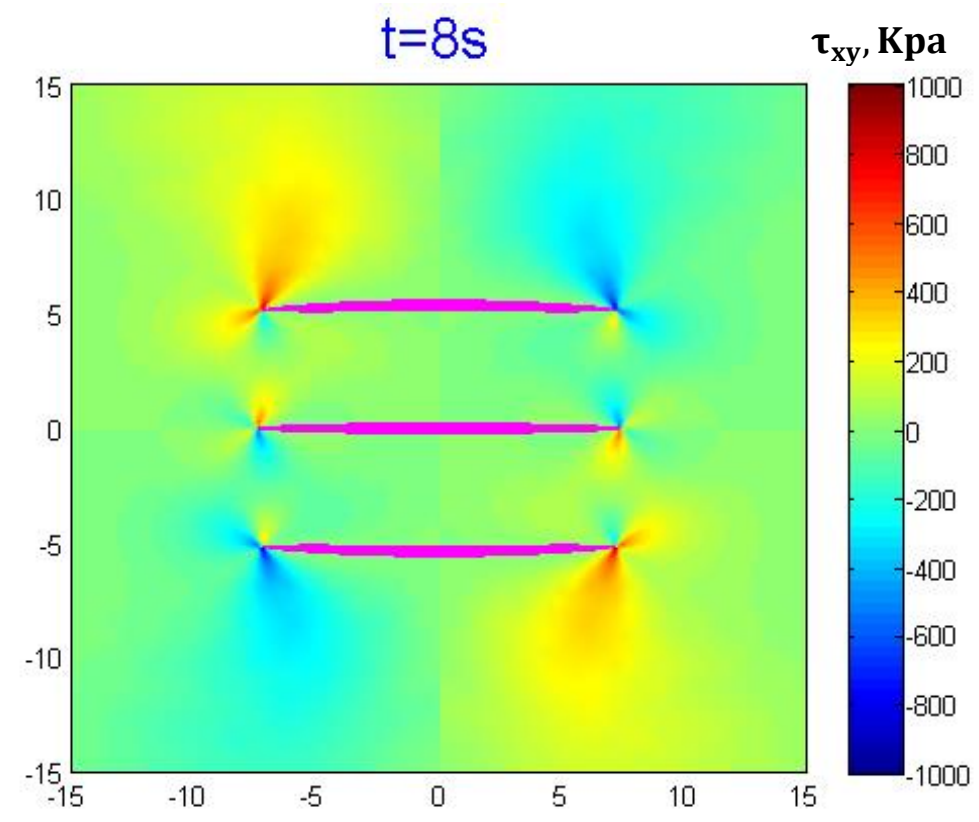

Figure 37. Shear stress of case 3 at $t=8 \mathrm{~s}$ 


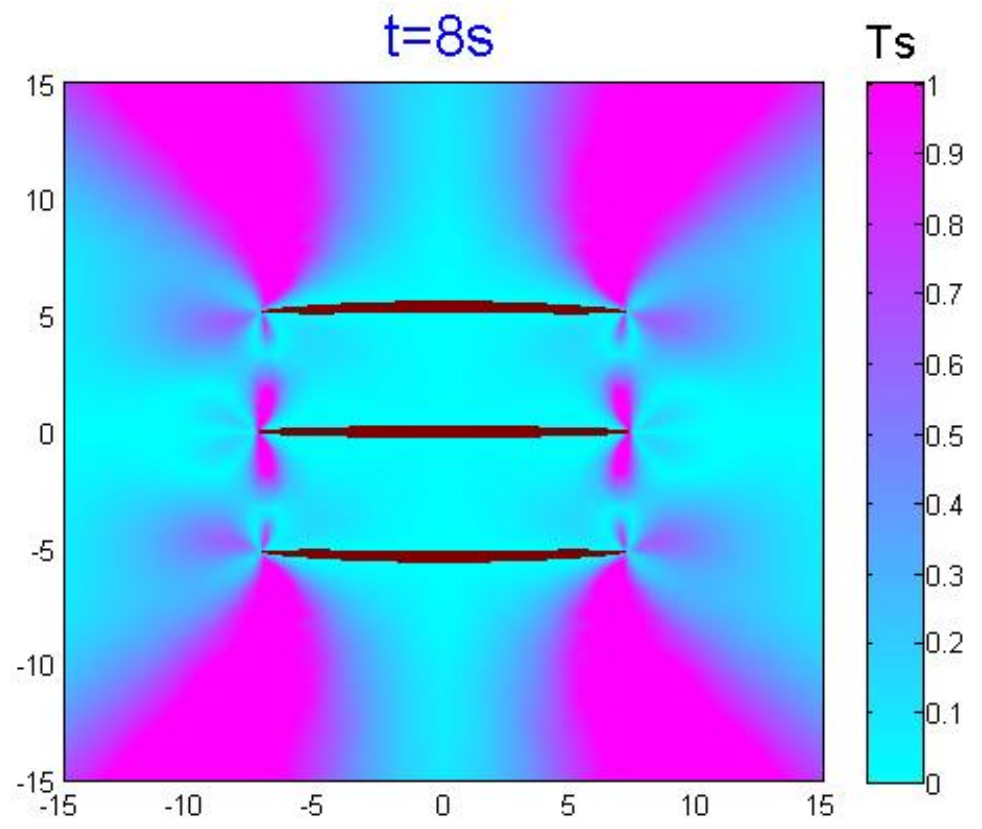

Figure 38. Slip tendency of case 3 at $\mathrm{t}=8 \mathrm{~s}$

Based on the dynamics of change in normal and shear stresses and following equation 8 in chapter 1 , figure 38 shows the calculated maximum slip tendency at $\mathrm{t}=8 \mathrm{~s}$ in the strike-slip faulting environment. It is common practice to assume slip tendency of 0.6 as the critical state for faults and discontinuities to slip. In figure 38 magenta parts cover unstable regions where since slip tendency is greater than 0.6. These regions fall at fracture tips and wings out from side fractures. The stable regions with slip tendencies less than 0.6 are mostly between and perpendicular to the fractures. Unstable regions where the failure in discontinuities occur can be recognized as higher permeability areas where improve the efficiency of the hydraulic fracturing stimulations. 


\section{CHAPTER 5: Discussions and conclusions}

\subsection{Discussions}

Multiple cases with different fracture number, fracture spacing and rock mechanical heterogeneities have been successfully simulated. Although results of these cases are derived under specific conditions described in table 1 , our simulation model covers different fracturing regimes and fluid characteristics and can be applied for multiple hydraulic fractures simultaneously created in heterogeneous medium.

The underlying theoretical basis of multiple hydraulic fracturing is the coupling of governing equations, which are mass conservation, momentum conservation, leak-off control and fracture propagation. With the fully coupled and discretized model using finite element method, the stress and displacement of whole model at any time step can be obtained describing the dynamics of fluid flow and fracture propagation.

The surrounding stress state of the fracture will be changed once a hydraulic fracture propagates. If multiple fractures propagate simultaneously, the mechanical interactions between them will impact their geometries such as fracture length and width. This can significantly impact the efficiency of hydraulic fracturing process by increasing the productivity index due to higher contact area and fracture conductivity.

We also investigated the effect of heterogeneity implied using hydraulic fracturing in composite model where heterogeneity is defined in rock mechanical properties by different Poisson's ratio and Young's modulus. Results show that the location of boundary between materials has minimum influence on the fracture propagation if the heterogeneity is defined using Poisson's ration. However, the fracture geometry will significantly be affected by reservoir heterogeneity if fracture passes through the interface and heterogeneity is defined by changing in Young modulus. 


\subsection{Conclusions and recommendations for future work}

In this thesis work, multiple hydraulic fracturing with different number of fractures, fracture spacing and rock properties were successfully simulated. The main findings are concluded as follows:

1. The fractures geometry and propagation rate is significantly affected by the number of fractures and their spacing. In general, the fracture number has a positive correlation with fracture length (or propagation rate) and a negative correlation with fracture width. Fracture spacing, however, has a negative correlation with fracture length (or propagation rate) and a positive correlation with fracture width. Mechanical interaction between fractures that leads to higher compressive stress between fractures is mainly impacting the dynamics of fracture propagation and geometry in multiple-fractures generated simultaneously in the medium. The mechanical interaction becomes stronger if fracture number increases and weaker if fracture spacing increases.

2. Composite model simulations show that heterogeneity in different materials play a minimum role in fracture propagation if the fracture does not cross the boundary between two materials. However, the propagation will be influenced if fracture crosses interface between two materials and heterogeneity in rock mechanical properties is defined by changing in Young modulus of two materials.

3. Slip tendency analysis based on coulomb criteria clearly shows the possible fault reactivation zones are around edge fracture tips and stable zones are mostly between and perpendicular to the fractures.

This study provides us advanced understanding of multiple hydraulic fracturing stimulation and dynamics of fracture geometry, propagation rate and stress change in surrounding areas. Moreover, the work is important for the development of sound numerical hydraulic fracturing optimization models. 
More investigation is needed in multiple hydraulic fracturing in heterogeneous porous media where the heterogeneity is defined in different rock properties and in-situ stress distribution with a layer, since this study only considers the effect of variation in Poisson's ratio and Young's modulus in composite model. Also, heterogeneity with pre-existing faults should be considered. Advanced understanding of multiple hydraulic fracturing in heterogeneous reservoir can help us find the optimal hydraulic fracturing procedure, which can ultimately maximize the gas production. 


\section{REFERENCES}

1. Hydraulic Fracturing: Unlocking America's Natural Gas Resources. American Petroleum Institute Report, July 2014.

2. Adachi, J., Siebrits, E., Peirce, A. and Desroches, J. 2007. Computer simulation of hydraulic fractures. International Journal of Rock Mechanics \& Mining Sciences, 44(2007):739-757.

3. Bao, J.Q., Fathi, E. and Ameri, S. 2014 in press. Investigation of hydraulic fracturing propagation Regimes in the Plane Strain Model. International Journal for Numerical and Analytical Methods in Geomechanics.

4. Batchelor, G.K. 1967. An introduction to fluid dynamics. Cambridge, U.K., Cambridge University Press.

5. Boone, T.J. and Ingraffea, A.R. 1900. A numerical procedure for simulation of hydraulicallydriven fracture propagation in poroelastic media. International Journal for Numerical and Analytical Methods in Geomechanics, 14(1): 27-47.

6. Boyer, C., Kieschnick, J., Suarez-Rivera, R. et al. 2006. Producing gas from its source. Oilfield Review, 18(3): 36-49.

7. Bunger, A.P., Detournay, E. and Garagash, D.I. 2005. Toughness-dominated hydraulic fracture with leak-off. International Journal of Fracture, (134): 175-190.

8. Bunger, A.P. 2012. Parameters affecting the interaction among closely spaced hydraulic fractures. SPE Journal, 292-306.

9. Bunger, A.P. 2013. Analysis of the power input needed to propagate multiple hydraulic fractures. International Journal of Solids and Structures, 50(10): 1538-1549.

10. Carter, R.D. 1957. Optimum fluid characteristics for fracture extension. ASME Spring Meeting, Mid-Continent District, Tulsa, OK, 1957.

11. Cheng, Y. 2009. Boundary element analysis of the stress distribution around multiple fractures: implications for the spacing of perforation clusters of hydraulically fractured horizontal wells. Paper SPE 125769 presented at the SPE Eastern Regional Meeting, Charleston, 23-25 September.

12. Cheng, Y. 2012. Mechanical interaction of multiple fractures-exploring impacts of the selection of the spacing number of perforation clusters on horizontal shale-gas wells. SPE Journal, 17(4): 992-1001. 
13. Crittendon, B.C. 1959. The mechanics of design and interpretation of hydraulic fracture treatments. Journal of Petroleum Technology, (October):21-29.

14. Desroches, J. and Thiercelin, M. 1993. Modeling the propagation and closure of microhydraulic fracturing. International Journal of Rock Mechanics and Mining Science \& Geomechanics Abstracts, (30): 1231-1234.

15. Devloo, P.R., Fernandes, D.P., Gomes, M.S., Bravo, C.M. and Damas R.G. 2006. A finite element model for three dimensional hydraulic fracturing. Mathematics and Computers in Simulation, (73): 142-155.

16. Economides, M.J. and Martin, T. 2007. Modern Fracturing: Enhancing Natural Gas Production. Energy Tribune Publishing Inc., Houston, Texas.

17. Fisher, M.K., Heinze, J.R., Harris, C.D. et al. 2004. Optimizing horizontal completion techniques in the Barnett shale using microseismic fracture mapping. Paper SPE 90051 presented at SPE Annual Technical Conference and Exhibition, Houston, 26-29 September.

18. Garagash, D. 2006. Propagation of a plane-strain hydraulic fracture with a fluid lag: Earlytime solution. International Journal of Solids and Structures, 43(43): 5811-5835.

19. Garagash, D.I., Detournay, E., and Adachi J.I. 2011. Multiscale tip asmyptotics in hydraulic fracture with leak-off. International Journal of Fluid Mechanics, (669): 260-297.

20. Geertsma, J. and de Klerk, F. 1969. A rapid method of predicting width and extent of hydraulically induced fractures. Journal of Petroleum Technology, (21): 1571-1581.

21. Green, A.E. and Sneddon, I.N. 1950. The distribution of stress in the neighbourhood of a flat elliptical crack in an elastic solid. Proceedings of the Cambridge Philosophical Society, (46):159-163.

22. Harrison, E., Kieschnick, W.F. and McGuire, W.J. 1954. The mechanics of fracture induction and extension. Petroleum Trans AIME, (201): 252-263.

23. Holditch, S.A. 2007. Hydraulic fracturing: overview, trends, issues. Presented at DEA Workshop, Galveston, 20-21 June.

24. Howard, G.C. and Fast, C.R. 1957. Optimum fluid characteristics for fracture extension. Drilling Production Practice, (24): 261-270.

25. Hu, J., Garagash, D.I. 2009. Plane-strain propagation of a fluid-driven crack in a permeable rock with fracture toughness. Journal of Engineering Mechanics, 136(9): 1152-1166. 
26. Jaeger, J.C., Cook, N.G.W. and Zimmerman, R. 2007. Fundamentals of rock mechanics (4th ed.), Wiley-Blackwell.

27. Khristianovic, S.A. and Zheltov, Y.P. 1955. Formation of vertical fractures by means of highly viscous liquid. Proceedings of the fourth world petroleum congress, 579-586.

28. Lecampion, B. and Detournay, E. 2007. An implicit algorithm for the propagation of a hydraulic fracture with a fluid lag. Computer Methods in Applied Mechanics and Engineering, (196): 4863-4880.

29. Lisle R.J. and Srivastava, D.C. 2004. Test of the frictional reactivation theory for faults and validity of fault-slip analysis. Geology, 32(7): 569-572.

30. Lister, J.R. 1990. Buoyancy-driven fluid fracture: the effects of material toughness and of low-viscosity precursors. Journal of Fluid Mechanics, (210): 263-280.

31. Mader, D. 1989. Hydraulic proppant fracturing and gravel packing. Elsevier Science Publishing Company Inc., 16.

32. Majer, E.L., Baria, R., Stark, M. et al. 2007. Induced seismicity associated with enhanced geothermal systems. Geothermics, 36(3): 185-222.

33. McClure, M.W. and Horne, R. N. 2011. Investigation of injection-induced seismicity using a coupled fluid flow and rate/state friction model. Geophysics, 76(6): 181-198.

34. Morrill, J. and Miskimins, J. 2012. Optimizing hydraulic fracture spacing in unconventional shales. Paper SPE 152595 presented at Hydraulic Fracturing Technology Conference, Woodlands, 6-8 February.

35. Moschovidis, Z. et al. 2000. The Mounds drill-cuttings injection field experiment: final results and conclusions. Paper SPE 59115 presented at the IADC/SPE drilling conference, New Orleans, 23-25 February.

36. Morris, A., Ferrill, D.A. and Henderson, D.B. 1996. Slip-tendency analysis and fault reactivation. Geology, 24(3): 275-278.

37. Nordgren, R.P. 1972. Propagation of a vertical hydraulic fracture. SPE Journal, 12(8): 306314.

38. Olson, J. and Dahi, A. 2009. Modeling simultaneous growth of multiple hydraulic fractures and their interaction with natural fractures. Paper SPE 119739 presented at Hydraulic Fracturing Technology Conference, Woodlands, 19-21 January. 
39. Ozkan, E., Brown, M., Raghavan, R. and Kazemi, H. 2009. Comparison of fractured horizontal-well performance in conventional and unconventional reservoirs. Paper SPE 121290 presented at the SPE Western Regional Meeting, San Jose, 24-26 March.

40. Paris, P.C. and Sih G.C. 1965. Stress analysis of cracks, in fracture toughness testing and its application. American Society for Testing and Materials. 30-83.

41. Perkins, T.K. and Kern, L.R. 1961. Widths of hydraulic fractures. Journal of Petroleum Technology, 13(9): 937-949.

42. Pine R.J. and Cundall, P.A. 1985. Applications of the fluid-rock interaction program (FRIP) to the modelling of hot dry rock geothermal energy systems. Paper presented at Proceedings of the international symposium on fundamentals of rock joints, Bjorkliden, September, 293-302.

43. Ptolemy, C. 1952. The almagest. Book III (transl. R.C. Taliaferro. 1938. Encyclopedia Britannica, Inc. London. Repr.), 130.

44. Soliman, M.Y., Hunt, J.L. and Azari, M. 1999. Fracturing horizontal wells in gas reservoirs. SPEPF 14(4): 277-283.

45. Spence, D.A. and Turcotte, D.L. 1985. Magma-driven propagation of cracks. Journal of Geophysical Research, (90): 575-580.

46. Sneddon, I.N. 1946. The distribution of stress in the neighbourhood of a crack in an elastic solid. Proceedings of the Royal Society of London, (187): 229-260.

47. Sneddon, I.N. and Lowengrub, M. 1969. Crack problems in the classical theory of elasticity. New York: John Wiley \& Sons.

48. Tsai, V.C. and Rice, J.R. 2010. A model for turbulent hydraulic fracture and application to crack propagation at glacier beds. Journal of Geophysical Research, (115): 1-18.

49. Van der Pluijm, B.A. and Marshak, S. 2004. Earth structure: An introduction to structural geology and tectonics. New York: WW Norton, 2nd edition.

50. Veatch, R.W., Moschovidis, Z.A. and Fast, C.R. 1989. An overview of hydraulic fracturing. In: Gidley, Holditch, Nierode, Veatch, editors. Recent advances in hydraulic fracturing. Monograph, Richardson: Society of Petroleum Engineers, (12): 1-38.

51. Yau, J.F., Wang, S.S. and Corten H.T. 1980. A Mixed-mode crack analysis of isotropic solids using conservation laws of elasticity. Journal of Applied Mechanics, 47(2): 335-341. 